\title{
Design and optimization of self-deployable damage tolerant composite structures: a review
}

\author{
P. Fernandes ${ }^{a, b, *}$, R. Pinto ${ }^{a}$ and N. Correia ${ }^{a}$ \\ ${ }^{a}$ INEGI - Institute for Science and Innovation in Mechanical and Industrial Engineering, Porto, 4200-465, Portugal \\ ${ }^{b}$ FEUP - Faculty of Engineering of the University of Porto, Porto, 4200-465, Portugal
}

\section{ARTICLE INFO}

\section{Keywords:}

Damage tolerance

Deployable structures

Optimization

\begin{abstract}
A B S T R A C T
Composite deployable structures are becoming increasingly important for the space industry, emerging as an alternative to conventional metallic mechanical systems in space applications. In most cases, the life-cycle of these structures includes a single deployment sequence, once the spacecraft is in orbit. So long as reliability is ensured, this fact opens the possibility of using the materials past their elastic regime and, possibly, beyond the initiation of damage, increasing the efficiency and applicability of the developed designs.

This review explores this possibility, surveying the design of deployable structures, as well as the state of the art on the design and damage tolerance in composites. An overview of the developments performed on the topology optimization of composite structures is included for its novelty and potential application in the design of deployable structures. Finally, the possibility of combining these topics into a single efficient design approach is discussed.
\end{abstract}

\section{Introduction}

For the space industry, the design of light and compact structures capable of deploying, once the payload is in orbit, has been of significant interest for more than two decades [94, $119,187,284]$. This interest is based on the consequent increase in efficiency of the design of spacecraft, as they become capable of transporting more equipment while reducing costs associated with fuel consumption [119, 187]. Initial developments that used metals later used also more efficient and lighter composite systems [79, 213, 237, 265].

Stored elastic energy deployable structures have been the leading candidates for space applications. These structures are designed to be stored in a retracted form with the capability of self-deploying by releasing the elastic strain energy accumulated during the retraction / folding process, which occurs in the elastic regime [187]. The simplest implementation of this concept is image cited from referred to as "tape-springs" (Figure 1 [148]), of which an example is the steel tape measure (also known as carpenter tape). The first use of tape-springs as deployable structures dates to 1968 [256], which are a useful replacement to traditional hinge mechanisms since they provide high repeatability and pointing accuracy. Well-known applications include the monopole and dipole antennas of MARSIS (Mars Advanced Radar for Surface and Ionosphere Sounding) in 2003 (Figure 2 [159]) [159]. Nonetheless, tape-springs can also be adopted for self-deployable tensegrity structures and smart origami structures $[9,45,135]$.

Recently, the European Space Agency (ESA) identified telecommunication satellites as a possible application for this technology, with promising results, replacing mechani-

\footnotetext{
${ }^{*}$ Corresponding author

** Principal corresponding author

pnfernandes@inegi.up.pt (P. Fernandes)

ORCID(s): $0000-0002-2708-2160$ (P. Fernandes); $0000-0002-4869-131 \mathrm{X}$ (R. Pinto); $0000-0001-6486-3954$ (N. Correia)
}

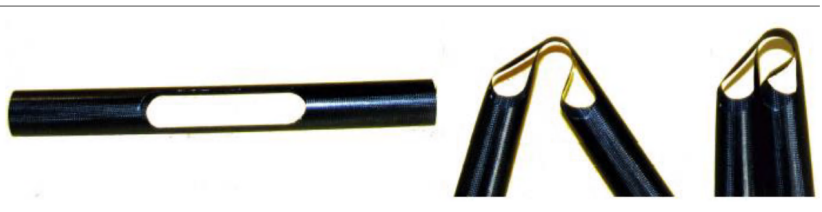

Figure 1: Tape-spring hinge in (from left to right) a deployed, partially contracted and fully contracted configurations (image cited from [148]).

cal arms with a lighter and compact solution. This trend is evident in projects proposed by ESA, such as the call for the development of an antenna deployment arm with integrated elastic-hinges, in 2016 [72]. However, this leads to two challenges. First, the design of a deployable structure should meet two opposing requirements: flexibility to sustain high strain deformations and rigidity to support external loads and/or reach certain natural frequencies $[79,119,123,159,184$, 239, 269], which may not always be possible. Second, the statement of work of the call presented in 2016 specifies that the deployment arm, developed for telecommunication purposes, should have a natural frequency of more than $1 \mathrm{~Hz}$ [72], which is 20 times higher than the required frequency for the monopole and dipole antennas developed for MARSIS [159] and even 100 times larger than similar solutions reported in the literature [151]. This scenario presents the need for a significant improvement compared to the state-of-the-art solutions and a simultaneously increased difficulty in complying with both requirements. Failing to balance these two requirements leads to one of two situations: either the structure becomes too flexible, failing to meet the rigidity requirements necessary to operate, or the structure becomes too rigid, making it impossible to retract / fold without damage initiation. Due to its novelty, information regarding the design and optimization of deployable structures considering multiple requirements is scarce $[77,79,80,147,149-151,154]$. 
Table 1

List of acronyms.

\begin{tabular}{|c|c|c|c|}
\hline Acronym & Meaning & Acronym & Meaning \\
\hline $\mathrm{ACO}$ & Ant Colony Optimization & MMA & Method of Moving Asymptotes \\
\hline BB & Barzilai-Borwein method & MWCNT & Multi-Walled Carbon Nanotubes \\
\hline BESO & $\begin{array}{l}\text { Bi-Directional Evolutionary Structural Opti- } \\
\text { mization }\end{array}$ & NCGC & $\begin{array}{l}\text { Non-Uniform Curved Grid-Stiffened Compos- } \\
\text { ite Structure }\end{array}$ \\
\hline BPNN & Back-Propagation Neural Network & NDFO & Normal Distribution Fibre Optimization \\
\hline CA & Cellular Automata & NDI & Non-Destructive Inspection \\
\hline CAI & Crash After Impact & NDSGA & Non-Dominated Sorting Genetic Algorithm \\
\hline CDM & Continuum Damage Mechanics & NGM & Normalized Gradient by Maximum \\
\hline CFRP & Carbon Fibre Reinforced Polymer & NSGA-II & $\begin{array}{l}\text { Non-Dominated Sorting Genetic Algorithm } \\
\text { II }\end{array}$ \\
\hline СТO & Concurrent Topology Optimization & NURBS & Non-Uniform Rational B-Spline \\
\hline CZM & Cohesive Zone Modelling & PCA & Principal Component Analysis \\
\hline DIC & Digital Image Correlation & PDS & Ply Drop Sequence \\
\hline DIW & Direct Ink Writing & $\mathrm{PHC}$ & Polynomial Homotopy Continuation \\
\hline DMO & Discrete Material Optimization & PPS & Permutation for Panel Sequence \\
\hline EBA & Enhanced Bat Algorithm & PSO & Particle Swarm Optimization \\
\hline EGO & Efficient Global Optimization & RBFNN & Radial Basis Function Neural Networks \\
\hline ESA & European Space Agency & RBRDO & $\begin{array}{l}\text { Reliability-based Robust Design Optimiza- } \\
\text { tion }\end{array}$ \\
\hline ESO & Evolutionary Structural Optimization & $\mathrm{RCC}$ & Representative Cell Configuration \\
\hline FEA & Finite Element Analysis & RIA & Reliability Index Approach \\
\hline FVF & Fibre Volume Fraction & RVE & Representative Volume Element \\
\hline GA & Genetic Algorithm & SA & Simulated Annealing \\
\hline GOLS & Gravity Offloading Systems & SFV & Streamline Function Value \\
\hline IHPA & Improved Hybrid Perturbation Analysis & SHM & Structural Health Monitoring \\
\hline LSF & Level-Set Function & SIMP & Solid Isotropic Material Penalization \\
\hline LSM & Level-Set Topology Optimization Method & SMM & Shape Memory Materials \\
\hline MARSIS & $\begin{array}{l}\text { Mars Advanced Radar for Surface and lono- } \\
\text { sphere Sounding }\end{array}$ & SSPO & Streamline Stiffener Path Optimization \\
\hline MIGA & Multi-Island Genetic Algorithm & & \\
\hline
\end{tabular}

In other fields of application of composite materials, the design methodologies have evolved significantly. Concepts such as damage tolerance have been investigated, leading to an extensive characterization of composite materials under a considerable plethora of loading cases and operating conditions. Aeronautic and energy industries, amongst others, have adopted this concept as a means of increasing the efficiency and / or factor of safety in the designed structures. Also, the cost reduction associated with the maintenance or disposal of damaged parts [6, 162, 219, 286]. Similarly, topology optimization methods have been under the spotlight of many researchers [176, 248, 294], developing more refined methodologies that can be applied to more advanced materials.

Despite the novelty or interest of damage tolerance, topology optimization, and deployable structures, the literature available on the combination of any two of these concepts and their application to deployable structures is either scarce or non-existent. Furthermore, the review of the combination of the three domains is unexplored.

Bringing together the benefits of damage tolerance and topology optimization can significantly impact the design and application of deployable structures. This type of structural mechanism has unique requirements and operating conditions. The need to meet flexibility and stiffness requirements is a challenging and daunting task that, due to its contradictory nature, may not be accomplished and will limit the use of deployable structures. However, since during the expected operating life of most deployable structures only one deployment is expected, it may be acceptable to design a structure that initiates damage, in a controlled manner, during its retraction process. As a result, the need for a flexible design can be relaxed, making it easier to reach stiffness-related requirements. Therefore, the benefits of using topology optimization to search for optimal solutions could be enhanced with an approach that, not only leads to a more efficient design but also increases the design space and the number of possible solutions suitable for the respective application.

This literature review explores the possibility of using topology optimization with a damage tolerant design approach suitable for composite materials. To do so, the review is divided into three main sections. Section 2 reviews the methodologies applied to the design of self-deployable structures, section 3 addresses the design methods of composite structures, and section 3.2 presents an overview of the different topology optimization methods. Section 3.3 reviews the 


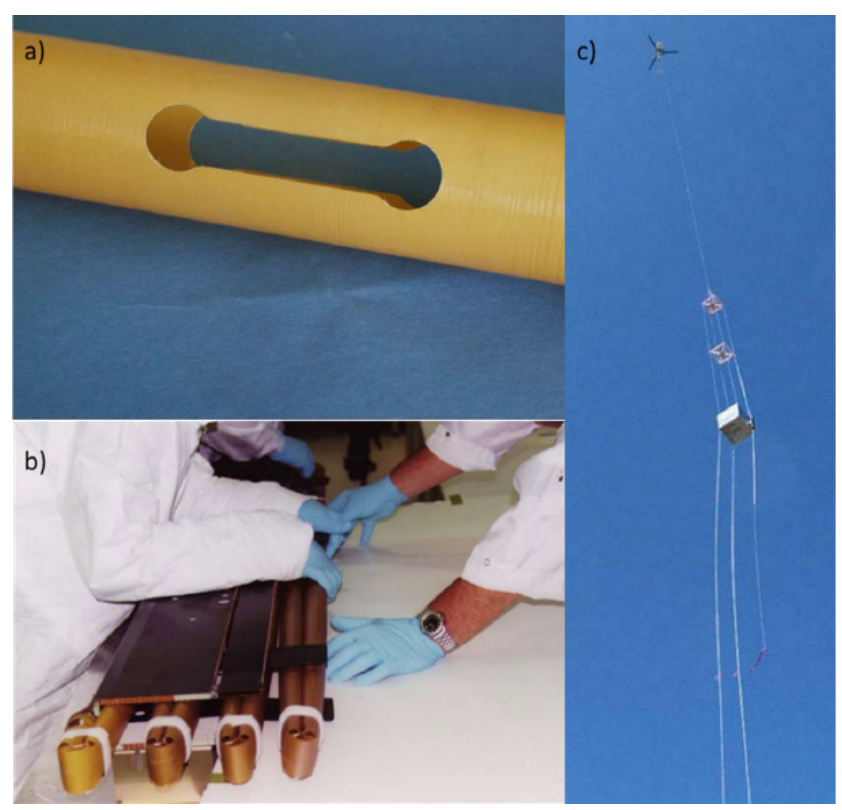

Figure 2: Elastic-hinge used in the monopole and dipole antennas of MARSIS. a) detail view of the elastic-hinge; b) stowage process; c) experimental deployment of the prototype using a helicopter (image cited from [159]).

use of damage tolerance. Finally, the possibility of combining these concepts into a methodology that leads to a topology optimized self-deployable damage tolerant composite structure is discussed in Section 4.

\section{Composite deployable structures}

The compact configuration characteristic of deployable structures is the result of the retraction process, which imposes the need for the structure to be flexible enough to sustain high-strain deformations [119, 187].

Similarly to the design process used for composite structures in the aeronautic sector [194], the following sub-sections overview the tools used to design deployable structures, including experimental characterization methods, numerical simulation approaches and design methodologies. For a more detailed review of different folding mechanism concepts and their trade-off, the interested reader is referred to [187] and to [75] for a more detailed classification.

\subsection{Experimental characterization of deployable tape-springs}

Despite the first research dating back to 1973 [156], reporting that the deployment of a tape-spring could cause a snap-through behaviour due to buckling loads, the literature available on methodologies to characterize tape-springs is quite limited. It was only in 1999 that Seffen and Pellegrino [213] proposed the first of five characterization methodologies used in the study and development of tape-springs.

Research reported in [213] has shown that the experimental characterization of this component can be performed by measuring the torque-angle relationship (Figure 3 [147]).

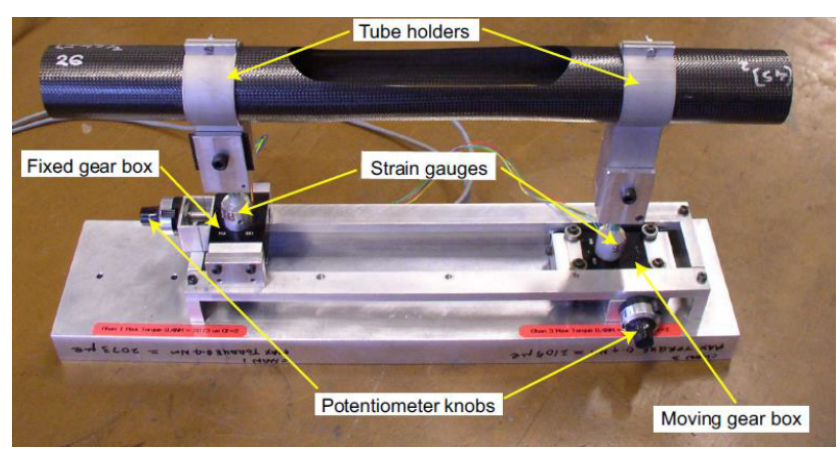

Figure 3: Example of an experimental setup used to measure the torque-angle curve (image cited from [147]).

Due to the curvature of the tape-spring, the behaviour is highly dependent on the direction in which the tape-spring is bent. When the torque applied causes tensile stresses on the edges of the tape-spring (considered positive torque, by convention), the tape-spring shows a linear behaviour followed by a sudden bend, which flattens the tape and causes a return to the linear behaviour. When a negative torque is applied, compressing the edges of the tape-spring, the linear behaviour ends sooner. Seffen and Pellegrino [213] reported that this case of loading promotes the deployment to occur along the same path, increasing the repeatability of the process. Later research [26, 80, 148, 151, 184, 206, 225, 231, 264, 281], more focused on composite materials, further supports the results obtained on the behaviour of tape-springs and on the use of torque-angle curves to characterize the retraction of tape-springs, leading to their application in several studies.

While the methodology described above is suitable to assess the retraction of the tape-spring, it does not address the dynamics involved in deployment. To study the release of the tape-spring, several authors [26, 64, 148, 151, 213] have used high-speed cameras to measure the angle formed by the tape-spring, or by the deployable structure, as a function of time. The main advantage reported is the possibility of measuring any over-shooting angle that may occur. In this context, over-shooting angle refers to the angle formed by the tape-spring due to buckling caused by compressive loads installed during the deployment process.

A relevant factor to be considered when designing a deployable structure is creep behaviour. The stowage of the deployable structure for long periods of time may cause anomalies in the deployment, as seen in the case of MARSIS [167]. The study of this phenomenon is image cited from performed on tape-springs, maintaining the retracted configuration for long periods of time [30, 124, 125, 127, 167, 169], although temperature has been used to accelerate the ageing process [31, 170]. Following this methodology, Kwok and Pellegrino [127] have been able to detect energy reductions of up to $60 \%$ when investigating the storage of composite tape-springs.

In some cases, Gravity Offloading Systems (GOLS) have been used to offset the effect of gravity. The purpose of this methodology is to replicate the operating condition of 
the tape-spring during deployment in space. In 2017, Mao et al. [158] used a GOLS that consisted of a set of braided cords that suspend the deployable structure. This allowed the structure to deploy along a plane parallel to the ground, resorting to a set of soft extension springs that compensated the changes in distance between the hanging points.

In summary, the characterization of the mechanical properties and behaviour of tape-springs is based on the experimental measurement of the torque involved in the retraction process and on the observation of the deployment. However, for being applied in space, the main obstacle is recreating the operating conditions. Offsetting variables such as the influence of gravity or air friction is a difficult task that may hinder the extensive testing of a design, particularly for solutions with low deployed stiffness or low deployment torque.

\subsection{Numerical modelling of composite deployable structures}

The design and development of deployable structures require the validation of the respective in-service conditions. However, replicating the operating conditions can be difficult, if not impossible [168]. This is evident in scenarios such as the one of MARSIS, where the deployable system used had a low deployment torque. This caused the deployment to be compromised by factors such as air friction and the influence of gravity [159]. Implementing numerical models that can accurately predict the behaviour and performance of the deployable system, taking into account the majority of factors that influence the process, would greatly aid the design process and allow a reduction in the experimental campaign necessary to validate each concept. Several authors $[26,49,62,63,89,102,110,125-127,147-$ $155,158,168,181,213,257]$ have published numerical modelling of deployable structures, where this topic is explored at different scales, from the micro to the macro-scale. Before reviewing the topics mentioned, and although not directly related to deployable structures, the interested reader is referred to [182] for a brief review on the numerical modelling of thermal conductivity of composite materials, which will not be addressed in this section.

In 2011, Mallikarachchi et al. [147, 151, 155] explored the possibility of using a micro to macro-scale approach to model an elastic-hinge during both deployment and retraction processes. Here, a failure criterion developed specifically to analyse plain-weave carbon fibre reinforced polymer (CFRP) under in-plane, bending, and the combined effect of in-plane and bending loads was considered. At the micro-mechanical scale, the authors estimated the tow elastic properties using the rule of mixtures and semi-empirical relations, detailed in [97], to determine the Poisson's ratios, longitudinal and transverse extensional modulus, and the shear modulus. Then, at a meso-scale level, the authors recreated the tow's crosssection architecture, the waviness of the fabric used and the ply arrangement considering geometric data obtained from the material microscopic analysis. The tows were modelled as wavy beams, defined by a sine wave, according to [266]. For the ply arrangement, Mallikarachchi included 6-node

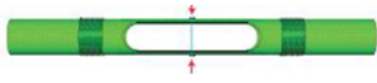

(a) Undeformed configuration

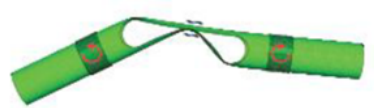

(c) Release of contact between hinge and rigid plates

Figure 4: Stages of the retraction (or folding) process simulation (image cited from [155]).

triangular prisms in the gaps formed between tow surfaces, representing additional neat resin. This approach would later lead the author to adjust the fibre volume fraction (FVF) within the tow to achieve a value equal to the one measured experimentally. Before transitioning to the macro-scale, the representative volume element (RVE) of the fabric was tested virtually and used to homogenize the ply properties.

The macro-scale model was implemented in ABAQUS ${ }^{\circledR}$ [157] using an explicit formulation that considered the interaction of the elastic-hinge with solid elements that replicate the experimental testing process used to obtain the torque-angle curve. These solid elements represent the two holders that support the elastic-hinge on each end, and are used to apply: 1) a torque that forces the system to fold; and 2) a pair of solid plates, responsible for pinching the tape-springs and flattening them before initiating the retraction process [147].

The sequence of steps of the retraction process recreated by the author is described in Figure 4 [155]. However, during the experimental validation of the numerical model, the author would suppress the pinching step, reporting that this was a manual step and, therefore, its removal would increase the repeatability and better standardize the experimental testing process. In other scenarios $[151,155]$, the pinching step was included as a means of guaranteeing that the folding of the tape-springs would occur at their mid-longitudinal section.

Regarding the experimental validation of the model, the author reported the presence of instabilities reflected as an oscillating movement of the elastic-hinge during the simulated retraction process. This divergence between numerical and experimental results was overcome using a viscous pressure parameter that functions as a damping mechanism. The value of the viscous pressure was tuned iteratively, ensuring that the energy dissipated through viscous mechanisms remained below $1 \%$ of the energy balance of the system $[151,155]$.

The comparison between the experimental and numerical results indicates that the finite element simulations could capture the behaviour of the elastic-hinge. However, it revealed some significant differences in the estimation of the maximum torque applied during the deployment stage. Furthermore, the maximum torque observed during the retraction process was, approximately, two times larger than the maximum torque installed during deployment. The authors justify 
this difference as a characteristic of structures with an unstable post-buckling equilibrium path [155], as described by Brush et al. [33] and by Van der Heijden et al. [251].

Finally, Mallikarachchi et al. [152] defined a failure criteria suitable to analyse plain-weave CFRP in three different loading cases: failure due to in-plane, bending, and in-plane plus bending loads. According to this criteria, the absence of the pinching step would cause the initiation of damage during the retraction process due to the installed torque $[151,155]$.

The research developed by Mallikarachchi et al. [147$155]$ is quite significant in the field of deployable structures for its extensive scope and approaches. However, several other researchers made relevant contributions. Researches with similar approaches include: Seffen and Pellegrino (1999) for the full deployment simulation and initial design of a single tape-spring, Boesch et al. (2007), Givois et al. (2001) and Jeong et al. (2016) [26, 89, 110] for structures with multiple tape-springs, Mao et al. (2017) [158] for integral slotted hinges, and Cook and Walker (2016) [49] for the use of tape-springs in the deployment of an inflatable structure.

In 2016, Dewalque et al. [62] performed a quasi-static analysis to assess the influence of geometric and material parameters of a single beryllium copper tape-spring to assess the relationship between the bending moment and the rotation angle. The parametric analysis and the optimization process used in this research resulted in a tape-spring geometry that minimized the installed stresses, according to the Von-Mises failure criterion, while maximizing the range of motion.

Nonlinear dynamic analysis was also used to evaluate buckling, hysteresis and self-locking phenomena that characterize the deployment of tape-springs. Walker and Aglietti (2004) [257] addressed the retraction and deployment of a tape-spring but considered a complex three-dimensional array fold. Hoffait et al. (2010) [102] addressed the hysteresis and buckling phenomenon observed during the deployment using a geometry similar to the one patented in [256], while Dewalque et al. (2015) [63] focused on using both numerical and structural damping to accurately simulate the deployment behaviour of tape-springs.

The viscoelastic effect that tape-springs may suffer due to the long-term stowage has also been addressed in the literature. Kwok and Pellegrino $(2011,2013)$ [125, 127] successfully captured the viscoelastic effect of the stowage implementing finite-element simulations based on linear viscoelastic material models. In 2012, the same authors [126] presented a micro-mechanical finite element model and used it to study the deployment and recovery of a bent thin-walled viscoelastic tape-spring. The outcome was a close agreement between numerical and experimental results. Nevertheless, the model was difficult to implement in the deployment simulation of a complete structure due to its expensive computational cost. In 2013, Peterson and Murphey [181] have shown through experimental test results, modified micromechanics and classical laminate theory analysis that the longitudinal and transversal bending stiffness of the tape-springs decreases with the shear modulus over time. The results obtained were $10 \%$ lower than expected, which were justified by inaccura- cies in the thickness of the material.

The literature on the numerical modelling of composite deployable structures focuses two different topics: the stowage and/or deployment sequence and the structural behaviour. The analysis of the stowage and/or deployment sequence is mainly concerned with the accurate representation and prediction of the kinematic movement, especially those that result from the release of the strain energy stored during the retraction process. On the other hand, the structural analysis addresses the integrity of structure from two different points of view. The first, considering the internal loads resulting from the deployment sequence, which can often rely on multi-scale approaches to bring together the properties of the 213domposite material observed at a micro-scale and the loads that result from the movement of the structure at a macroscale. The second, considers the changes in properties of the material, especially due to relaxation phenomenon that result from extended stowage periods.

\subsection{Design of composite deployable structures}

The successful design of a deployable structure relies on the capability of achieving the necessary flexibility to sustain the high-strain deformations that allow their characteristic high-compact ratio [187].

Soykasap et al. (2004) [233] reported the design process of a deployable reflector concept. The authors used the maximum strain failure criterion to theoretically estimate the minimum bend radius that the CFRP sheets could sustain without initiating damage. The estimation was experimentally validated but the authors mentioned that the use of angle plies on the outer surfaces of the plate significantly decreased both the predicted and the minimum measured bend radius. The size of the cut-outs was defined considering that, although they reduce the maximum strain in the region close to the hinge, their dimension should be as small as possible to avoid the loss of stiffness in the structure. Furthermore, the authors observed that reinforcing the stress concentration points near the edges of the cut-out would increase the maximum stress due to the increased thickness of the composite. Parameters such as the length and width of the cut-out were defined taking into consideration the minimum bend radius that would allow a two-step retraction sequence (Figure 5 [233]). In 2008, the authors also applied this approach to a similar structure, imposing a minimum natural frequency requirement [232].

In 2010, Mallikarachchi and Pellegrino [149] addressed the capability of an elastic-hinge being able of being bent at $180^{\circ}$ through a parametric study using a finite element model. Each combination of parameters was evaluated through a structural finite element analysis (FEA), assessing if there was initiation of damage according to the maximum strain failure criteria. The authors then selected three possible designs that were further analysed in [150]. This time, the elastichinges were simulated considering their stowed configuration around a satellite and were evaluated according to their own failure criteria proposed in [152], suitable for the evaluation of plain-weave CFRP. 


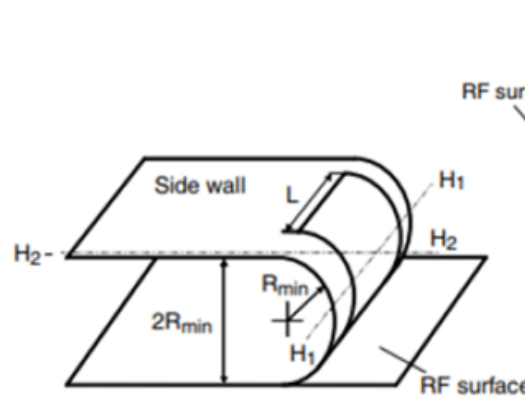

(a)

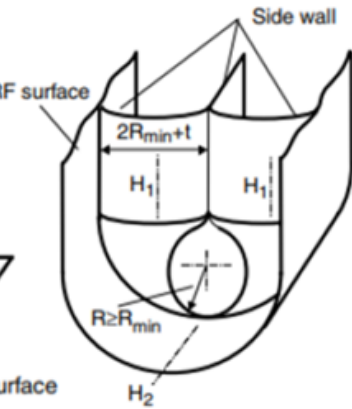

(b)
Figure 5: Representation of the two-step retraction sequence. (a) Folding of side wall about line $\mathrm{H} 1 \mathrm{H} 1$; (b) folding of RF surface around the folded side wall (image cited from [233]).

Tan and Pellegrino $(2006,2012)[238,239]$ reported the development of a cap that improved the deployed stiffness of a deployable reflector. The stiffener was applied on the edges of the tape-spring that deploys the structure. The authors applied the Hooke and Jeeves direct search method [104] to identify the optimal angle and width of the stiffener, as well as the angles of slit at end of the diameter. Each solution was evaluated by means of a FEA in ABAQUS ${ }^{\oplus}$ [157] to determine the influence on the natural frequency of the deployed structure. This methodology led to an improvement of the stiffness and natural frequency by a factor of 31 and 4 , respectively, with a mass increase of only $16 \%$ when comparing to the same solution without the stiffener.

The use of shape memory materials (SMM) in deployable systems deserves to be mentioned. To prevent the latch-up shock from the deployment of high-stiffness tape-springs, Jeong et al. (2014) [110] included a shape memory alloy tape aligned with the tape-spring. The reason behind this design is the transition from a dynamic, and possibly unstable, deployment to a quasi-static one. A sequential quadratic programming algorithm was used to solve the optimization problem, iterating over the length, thickness (number of plies) and width of the tape-springs. The dimensions of the shape memory alloy used as a damping mechanism were selected considering the torque applied by the tape-spring. The use of SMM has been a point of interest for several studies $[54,128,132,133,139,141]$, which are not within the scope of the present review. For more information and for an updated review on the use of SMM in deployable systems, the interested reader is referred to $[132,141]$.

Chu and Lei (2014) [48] presented a design theory and dynamic analysis of a lenticular boom with a mechanism that aids the deployment and retraction process. The design process began with the definition of a relationship between the geometry of the lenticular boom and properties or factors, such as: bending stresses, torsional stresses, natural frequency of the structure and the strain energy involved. The analytical expressions defined were then used in an optimization cycle, using the sequential quadratic programming method. The objective of this optimization was to minimize the stress installed in the structure considering geometric and natural frequency constraints.

To design the tape-springs of a deployable solar panel, Dewalque et al. (2016) [62] used a parametric study and an optimization algorithm to explore possible combinations of thickness, radius of curvature and subtended angle of the tape-spring. In this case, and due to the nature of the selected algorithm (fmincon in MATLAB [161]), the parametric study served as a means of performing an educated initial guess of the optimal solution. The optimization algorithm was used in conjunction with the software SAMCE [244], which simulated the performance of the geometry selected by the algorithm when retracting $120^{\circ}$ and posterior deployment.

Wu and Vinquerat (2017) [269] designed a braided bistable carbon-epoxy tube considering the optimization of its natural frequency. To do so, the braid angles and stacking sequences were optimized, using the coiled diameter of the structure as a constraint and the maximum and minimum physically achievable braid angles as bounds. The authors utilized a pattern search method, available in MATLAB global optimization toolbox [161], to define the parameters to be used by a Python [196] script to generate the models to be simulated in ABAQUS ${ }^{\circledR}$ [157]. The implemented design process allowed the authors to find a design that met the defined requirements. During this process, it was also observed that the braid angle had a greater influence in the natural frequency than the ply location within the stacking sequence for long slender designs, whereas both factors have significant influence in the natural frequency of shorter designs.

Between 2015 and 2019, Sakovsky et al. [203-206] have researched the use of a dual-matrix concept to design deployable antennas. According to the authors, thin shell deployable structures offer an efficient packaging but reduced surface precision, while elastomer composite shells have a smaller fold radius upon packaging but are limited by the stiffness of the deployed structure. Therefore, the concept of a dual-matrix composite, consisting of a continuous CFRP with localized elastomer matrix embedded in hinge regions, should allow for small fold radii, strain energy deployment, high deployed stiffness, and enable larger antenna apertures. The authors have compared dual-matrix structures with existing antenna designs considering both structural and electromagnetic performances. This approach led to the design of a deployable dual-matrix composite conical log spiral antenna to be used on CubeSats, which outperformed existing off-the-shelf designs regarding gain, bandwidth, and packaging efficiency.

In other publication [279], Yang et al. (2019) presented the design of a self-deployable composite boom with an Nshaped cross-section. The design process adopted by the authors includes four distinct steps. The first design of experiments approach was used, where the sampling designs for the N-boom were created. Then, each design sample was evaluated through numerical analysis in ABAQUS ${ }^{\circledR}$ [157]. The third step was the use of the response surface method to create a surrogate model of the bending stiffness around the $\mathrm{xx}$ and yy axes (transverse) and torsional stiffness around the $\mathrm{zz}$ axis (longitudinal). Finally, the authors applied a modified non-dominated sorting genetic algorithm (NDSGA) to per- 
form a multi-objective optimization, maximizing the bending stiffness around $\mathrm{x}$ and $\mathrm{y}$ axes and the torsional stiffness around the $\mathrm{z}$ axis. A mass constraint was imposed, and the two design variables were selected, defining the bonded web height and central angle of the middle tape. The authors concluded that the final design obtained was feasible and that the surrogate model predicted accurately the behaviour of the deployable system with a maximum error of $8.81 \%$.

More recently, Ferraro and Pellegrino (2019) [80] explored the use of a topology optimization approach to define the geometry of the cut-outs in a composite deployable corner joint. The adopted topology optimization method differs from the original concept proposed by Bendsøe and Kikuchi in 1988 [23], where the element of a material volume had their density changed depending on a given criteria (such as maximizing the stiffness). Instead, two different approaches were used and compared in [80]: the first was the parametric optimization of the points defining a spline, and the second was a LSM approach. In the first case, the design variables were eight points that could move freely in a constrained space, defining the shape of a spline. The Basin-Hopping algorithm was then used, considering the minimization of the failure index at each consecutive folding step, while maximizing the bending stiffness of the deployed joint. The second approach allowed for a broader exploration of shapes, number, and cutouts position. In this case, the definition of the shape of the cut-out is achieved through the intersection of a cutting-plane with a 3-D basis function, $z=f(x, y)$. Two basis functions were investigated, a series of cosines squared, and a series of cosines and sines squared. The optimization process then iterates over the z-coordinate at which the plane will intersect the basis function. To increase the diversity of the solutions, the authors allowed the cutting plane to have an inclination angle in relation to the $x-y$ plane. Both approaches were used to generate the geometry to be simulated in a finite element model, in ABAQUS ${ }^{\circledR}$ [157], that was previously developed and validated in [79]. Despite the innovative approach, the solutions obtained by both methods did not meet the failure criteria. However, the authors mentioned that the designs proposed by the optimization method led to a reduction of the area where damage initiated [80].

In previous research, Fernandes et al. (2020) [77] attempted the optimization of a self-deployable elastic-hinge considering the requirements defined by ESA in the statement of work published in 2016 [72]. The authors considered a total of 10 design variables, two defined the number of plies and orientation of the composite laminate, and a set of eight variables described the geometrical shape of a slot cut-out (inspired in the work of Mallikarachchi et al. [150]). The optimization approach consisted of using a genetic algorithm (GA) to perform a global search, iterating over a discrete version of the design variables, followed by a continuous and local search using a particle swarm optimization (PSO) algorithm. The objective was the minimization of the maximum index of failure resulting from the following set of criteria: Hashin's, Azzi-Tsai-Hill, Tsai-Hill, Tsai-Wu, and Maximum stress failure criteria. Additionally, the authors penalized solutions with a natural frequency below the minimum requirement imposed in [72] equivalent to $1 \mathrm{~Hz}$. Although the final design obtained met the frequency requirement, the algorithm did not minimize the maximum index of failure below the maximum acceptable value of 1.0, which indicates damage initiation. By means of a parametric analysis, the authors concluded that the design variables suggested in the literature are scarce and limit the design space and possibly exclude better design possibilities. The definition of the slot cut-out through a spline or the use of topology optimization has been identified as a possible subject of improvement.

In summary, the present literature review shows a clear evolution in the methodologies adopted to design deployable structures. The first approaches were based on analytical evaluation of the stress-strain state of the composite material, establishing a relationship between the maximum strain failure criteria and the folding radius $[232,233]$. This methodology was followed by parametric evaluations having finite element models as a valid resource, using either strain [149] or stressbased [150] failure criterion. Finally, the latest observable trend is the inclusion of optimization algorithms in the design process, as well as the inclusion of additional design constraints, such as the natural frequency of vibration, deployed stiffness or the deployment torque $[48,62,77,80,110,203-$ 206, 269, 279]. However, despite its novelty and popularity in several fields, it is notable the absence of topology optimization-based methodologies, with only one research exploring this possibility [80]. Additionally, it is notable that all design methodologies reviewed share a conservative approach, regardless of most deployable applications only being used a single time in their life-cycle. The use of damage tolerant designs, or allowing the initiation of damage, would allow to achieve more demanding requirements, such as higher natural frequencies or a larger deployment stiffness, which are yet to be addressed.

\section{Design of composite structures}

Section 2 addressed the different methodologies used to design a composite deployable structure. It became evident that the methodologies adopted image cited from involved the use of FEA and, more recently, the use of optimization methods. The purpose of applying these methodologies is, frequently, to achieve a high-strain capable design that complies with specific requirements, such as: minimum natural frequency, deployed stiffness, or deployment torque.

In other fields of application, damage tolerant design [6, $162]$ and topology optimization [23] are concepts and methods that have been extensively studied and applied to composite materials and their applications. However, when it comes to deployable structures, the information available on the use of these concepts is either scarce or non-existent.

The following three sub-sections review the literature available on the design of composite structures (3.1), topology optimization (3.2) and damage tolerance (3.3). However, the purpose is not to perform an extensive review on all the design and optimization methods but to focus on assessing 
the possible application of damage tolerance, topology optimization or other design methods to deployable structures and identify possible advantages of their use.

\subsection{Design methods}

In 2018, Xu et al. [275] and Nikbakht et al. [174, 175] have presented extensive state-of-the-art reviews on the different design methodologies applied to composite materials and structures. Both conclusions are similar, expressing the general interest of optimizing variables such as fibre orientation in each ply, ply thicknesses, ply number, and stacking sequence. The authors categorized the optimization methods into the following three groups: gradient-based methods, heuristic methods, and hybrid methods. Both research groups concluded that gradient-based methods are image cited from faster but may require information that is either unavailable or have a high computational cost. In contrast, heuristic methods that do not require gradient information have been widely used, with the most popular algorithms being: GA, simulated annealing (SA), PSO, and ant colony optimization (ACO). Finally, the authors have not observed a large application of hybrid methods but consider them a promising tool in the future, when including artificial intelligence. Xu et al. [275] mention the relevance of topology optimization applied to laminated composite structures for allowing the simultaneous design of the structural layout and of the fibre orientations.

This section will report and develop on the information published since the release of the reviews made by Xu et al. and Nikbakht et al. [174, 175, 275], sorting the work according to the use of heuristic (3.1.1), gradient-based (3.1.2), or hybrid and other methods (3.1.3). A brief discussion of these three sub-sections is presented at the end of Section 3.1.3. For its potential, interest and popularity, topology optimization methods will be addressed separately in Section 3.2.

\subsubsection{Heuristic methods}

In Jin et al. [112], the blending of a composite laminate (continuity of the composite stacking sequences as defined in [122]), is addressed proposing the Permutation for Panel Sequence (PPS) blending model, which is an improved version of the Ply Drop Sequence (PDS) concept. Both approaches use a GA whose population has three chromosomes. The first two define the fibre angle and guide distance. The third chromosome differs between PPS and PDS, representing a permutation variable or the existence/absence of a given ply, respectively. The authors state that this change allows the algorithm to avoid the problem of repeated search of discrete points in the design space for the previous PDS blending model, leading to faster convergence. An et al. (2019) [12] also addressed the blending of the composite material but included design constraints. The approach used is an extension of the two-level multi-point approximation method described in $[10,11,41]$. The process is divided into two phases. The first begins with an initial stacking sequence design that is used to generate a first-level approximation problem. A GA is used to decide the presence and absence of each ply in the initial design. To ensure the continuity and blending of the different laminate regions, the authors proposed a sharedlayer and local mutation method, which forces the individuals in the GA to satisfy the imposed blending rule. The second phase uses a second-level approximation problem to optimize the thickness of the retained layers as continuous variables. The authors efficiently obtained solutions that satisfy both design and manufacturing requirements and successfully applied them to the design of a satellite cylinder.

Regarding performance optimization of the composite, Esmaeeli et al. (2019) [73] used a multi-objective implementation of the ACO algorithm to optimize the characteristics of a multifunctional laminated composite. By changing the angles of the plies and simulating a RVE of the material, the authors were able to maximize the effective in-plane elastic constants. Conducting different benchmark problems, the authors observed a quick and successful convergence towards optimal ply angles and the determination of the Pareto optimal frontier regardless of the dimensions of the problem. Similarly, although on the design of active composites, Hamel et al. (2019) [96] studied and applied the use of an evolutionary based design method for $4 \mathrm{D}$ printed composites, where $4 \mathrm{D}$ refers to the time evolving shape of $3 \mathrm{D}$ printed parts. To do so, the authors combined an evolutionary algorithm with the finite element method to determine the distribution of active and passive material elements. The authors demonstrated the application of this method to single-objective and multi-objective optimization problems.

Neves Carneiro and Conceição António [57], applied a novel methodology, combining the Reliability Index Approach (RIA) [14] with the Reliability-based Robust Design Optimization (RBRDO) [55,56], to the design of a composite laminate structure. This bi-objective optimization problem aims at minimizing both the weight and the determinant of the variance-covariance matrix of the response functionals of the system (robustness), while considering displacement and stress constraints. The reliability assessment is performed in an inner cycle of the design optimization. The authors highlight the exclusive use of a GA with elitist strategy as the key concept of this methodology, avoiding the need for sensitivity analysis, convexity and continuity of the search space, and guaranteeing global convergence. With this approach, the authors were able to optimize the ply orientation and thickness of the laminate while considering: uncertainty in both random design variables and random parameters (robustness assessment) and uncertainty on the individual mechanical properties of each laminate (reliability assessment). More recently, Yoo et al. (2021) [282] proposed a novel multifidelity modelling-based optimisation framework, aimed at the robust design of composite structures. Through the use of high-fidelity model for exploitation and low-fidelity model for the exploration of the design space, the authors were capable of achieving computational time savings of at least $50 \%$ compared to conventional multi-fidelity and high-fidelity modelling methods. This method was successfully applied to the robust design optimization of a stiffened composite panel, considering design uncertainty under non-linear postbuckling regime. 
Seeking the simultaneous optimization of both composite geometries and laminate stacking sequence, San et al. (2019) [208] applied a multi-island genetic algorithm (MIGA) to maximize the natural frequency of a composite structure. The design variables that characterized the geometry were the points of a non-uniform rational B-spline (NURBS), defined as continuous variables. On the other hand, the ply orientation was defined as a discrete variable with four possible values $\left(0^{\circ}, \pm 45^{\circ}\right.$, and $\left.90^{\circ}\right)$. San et al. reached two main conclusions. First, that a two-phase optimization was seizing local suboptimal results, contrasting with a simultaneous optimization which led to the global optimum. Second, that increasing the number of control points of the NURBS led to improved optimal results due to the increase in degrees of freedom. These results are in line with the conclusions obtained by Fernandes et al. (2020) [77] when using the same design variables to optimize the design of a deployable elastic-hinge. However, instead of a MIGA, Fernandes et al. used a GA for a global discrete search, followed by a PSO approach for continuous local optimization.

\subsubsection{Gradient-based methods}

In 2018, Duan et al. [67] optimized the topology of a composite truss structure. The objective was to maximize the first natural frequency of the system, made of filament-wound profiles with a circular cross-section and a continuous winding angle. The design variables were the radius and composite orientation angle of each profile. The authors determined the sensitivity of the objective function to each variable and used the Method of Moving Asymptotes (MMA) [236] to update the design variables. The approach was tested and validated in both two and three-dimensional case studies.

Nasab et al. (2018) [74] used a gradient-based approach to the thickness optimization of stiffened composite skins, guaranteeing the blending of plies over individual panels. The approach considered design guidelines such as symmetry, covering ply, disorientation, percentage rule, balance, and contiguity of the layup. To do so, a stacking sequence table is generated and a level-set gradient-based method is used to optimize the location of ply drops. The objective of this procedure is to convert discrete design variables associated with the number of plies into a continuous problem. The output is the optimum thickness distribution over the structure in relation to a specific stacking sequence table. This method was applied to the 18-panel Horseshoe Problem and to the optimization of a composite stiffened skin of a wing torsion box. In comparison with a GA, the authors concluded that the approach proposed was, in general, faster, and less expensive. Avoiding the direct optimization of the ply-thickness and fibre orientation, Demir et al. (2019) [60] applied a leastsquare optimization approach, with continuity constraints, to optimize the lamination parameters of a composite [2]. The authors argue in favour of this parametrization as it leads to the stiffness becoming a linear function of the lamination parameters, instead of a nonlinear trigonometric function of the fibre angle, making it more suitable for gradient-based methods. Additionally, this parametrization accounts for any number of layers and possible fibre angles [2]. After obtaining the optimized lamination parameters, the authors used a material library consisting of desired fibre angle and stacking sequences. The material whose lamination parameters was most like the optimized result, was the material selected. In other research [218], Shafighfard et al. (2019) followed the same approach to determine the lamination properties of different open-hole composite plates, observing a $13 \%$ improvement in compliance of the final design when compared to other state-of-the-art optimization methods.

In 2019, Wang et al. [258] proposed the streamline stiffener path optimization (SSPO), a multi-scale-based method for curved stiffener layout design of non-uniform curved grid-stiffened composite structures with embedded stiffeners (NCGCs). The SSPO is based on 4 steps, starting from a homogenization-based analysis to calculate the unstiffened global model. Then, a discrete distribution of two-dimensional curved stiffener paths is converted into a continuous distribution of a streamline function values (SFVs) on a 3D level-set surface. Projected points with the same SFVs are then used to define one stiffener path. The contribution of stiffeners is considered in the global model through the calculation of equivalent material properties of a parallelogram representative cell configurations (RCCs), via homogenization. The third step is the optimization of the curved stiffener layout, achieved by means of a sensitivity-based shape design of the local parallelogram RCCs with analytical sensitivities. The final step is the maximization of the buckling load within a given weight, considering manufacturing, stiffener spacing and angle constraints. Wang et al. validated the effectiveness of steering the path of the stiffeners through the numerical evaluations of a laminate panel under compressive loads.

Oriented towards the design of additively manufactured components, Fernandez et al. (2019) [78] included manufacturing constraints of this process in the design of Direct Ink Writing (DIW) short carbon fibre and thermoset resin composites. The authors defined the extrudate trajectory as the contours of level-set functions, which define the orientation of the fibres, their FVF and hence the structural response of the composite. Using nonlinear programming and the finite element method to obtain information on the mass, compliance, and design sensitivities of the structure, it was possible to find a local optimal. In this process, the authors imposed constraints such as: no-overlap, no-sag, minimum allowable radius of curvature and continuity of the toolpaths that must begin and end at a boundary. Finally, the authors formulated a travelling salesman problem to determine the continuous shortest path for each layer, minimizing the manufacturing time. Shen and Branscomb (2020) [220] studied how to find the optimal material orientation of an anisotropic material in an additively manufactured structure. The authors proposed the use of a rationalized formula, referred to as normalized gradient by maximum (NGM), to calculate the step length of a gradient descent method and find an optimal material orientation that minimized/maximized the compliance of a structure under plane stress conditions. This method was compared with a stress based and a strain-based method. The 
strain-based method had the worst performance. The authors also observed that although the stress based method had a faster convergence, the combination of the NGM with the Barzilai-Borwein method (BB) provided a gradual change in orientation in the process and searches the maximum as well, making it a more general method and better suited to handle arbitrary constraints and loads in the finite element method.

In 2020, Nasab et al. [171] adopted a decomposition strategy for the structural optimization of a fibre-reinforced aircraft wing box, dividing the problem into a system-level and subsystem-level optimizations. The subsystem problem is the optimization of the ribs which are subjected to the crushing loads resulting from the bending of the wing. The system-level problem is the optimization of the wing-box skins, accounting for the effect of the skin design on the loads applied to the ribs. A principal component analysis (PCA) was used to assess the influence of the changes in loads on the ribs, increasing the numerical efficiency of the decomposition strategy. A level-set strategy that allows the use of both coarse and fine finite element models was adopted to solve the optimization problems in both system and subsystem levels. The results obtained by Nasab et al. show that the decomposition strategy allowed the solving of a complex problem at a reasonable computation cost.

\subsubsection{Hybrid and other methods}

Rongrong et al. (2018) [195] applied a hybrid approach to the design and optimization of a composite forward swept wing. The authors generated a surrogate model of the aeroelastic torsion divergence problem using radial basis function neural networks (RBFNNs), which was then solved with a GA. The objective was to minimize the deformation of the wing by optimizing the number of composite layers and their orientation, which were defined as a set of discrete possible values. The authors report that this process allowed a 32.5\% reduction of the displacement of the wing. Still related to the use of artificial intelligence, a multi-scale optimization and design approach is presented by Hai et al. (2020) in [173]. The authors aimed at maximizing the buckling load of several composite shells, with different cut-out geometries in their centre, by modifying a set of five parameters that define the geometry of the meso-scale RVE. The approach used begins at the micro-scale, estimating the properties of a fibre bundle through a FEA in ABAQUS ${ }^{\circledast}$ [157]. This information is introduced into the open source software TexGen [221], which can generate meso-scale models of the RVE of the composite tow. This model is used to estimate the mechanical properties of the material as a function of the configuration of the RVE. Finally, the mechanical properties of the material are introduced into a macro-scale numerical model, estimating of the buckling load. The data obtained from the buckling analysis was used to train a back-propagation neural network (BPNN). The BPNN was then integrated, with an Efficient Global Optimization (EGO) algorithm [114], allowing the iteration of the design variables and optimization of the design problem with a reduced computational cost.

Johnston et al. (2019) [113] proposed a methodology for the design of a composite hub-web structure that integrates a hybrid composite-steel gear. The geometry consists of a planar structure whose thickness decreases from the hub to the rim. The methodology proposed consists of several steps. The first is the evaluation of an initial simple design. Then, the information on the structural performance of the initial design is considered in a free-shape optimization, which applies orthotropic composite properties to a 3D element mesh of the hybrid gear structure, represented a bulk volume model. This optimization step aims at minimizing stresses or strains in the part while maintaining key design requirements, such as the connection to other components. The following step is the stress-constrained topology optimization of the result obtained so far, minimizing the weight or volume. In addition to the optimized topology, the expected output includes a loading map of the cross-section of the gear, indicating where continuous-fibre layers are required for greater strength and stiffness. Likewise, lower density filler layers can be added to more voluminous regions where load-bearing capabilities are less required. In case the filler layer is made of a different material from the continuous-fibre composite layer, a second free-shape optimization step is performed to minimize stress or strain in the filler region. Finally, the laminate sequence is optimized, leading to the final design.

Adopting the use of lamination parameters, Liu et al. (2019) [140] optimized the lay-up of a composite laminate with the Wittrick-Williams algorithm [267]. Then, instead of selecting a material based on an available library (as in [60, 218]), Liu et al. applied a logic-based procedure combining the branch and bound method with a global layer-wise technique to find the optimal stacking sequence that best matches the optimized lamination parameters. An alternative to this second step is presented and validated by Viquerat (2020) in [255], where a set of up to 12 lamination parameters are used to define a laminate configuration through a polynomial homotopy continuation (PHC) technique [191, 253]. The PHC treats the ply angles as continuous variables, taking any value between $-90^{\circ}$ and $+90^{\circ}$.

Khodaygan et al. (2020) [118] applied the multi-objective algorithm NSGA-II (Non-dominated Sorting Genetic Algorithm II) to the design of a stiffened laminated composite cylindrical shell with piezoelectric actuators. The objective was to maximize the buckling load and minimize the total weight. The design variables considered were the thicknesses of the three layers (composite, piezoelectric, and stiffener) constrained to a constant total shell thickness. To support the selection of solution from the Pareto fronts, the authors used the Shannon's entropy-based TOPSIS algorithm [249, 283], avoiding the use of weighting factors of the objective functions when selecting the final optimal design from the Pareto front. Considering similar approaches and conditions, Albanesi et al. (2020) [5] describe the design of a composite wind turbine blade. First, the authors utilized a GA to determine the optimal laminate layout in the outer shell skin of the turbine blade. Then, a topology optimization approach was applied to remove material from the shear webs, considering constraints on the tip displacement, stresses, natural vibration 
frequencies, and buckling phenomena. The sequential use of a GA and a topology optimization approach led to mass savings of up to $23 \%$ according to the authors.

Although the definition of ply orientation angles, considering a manufacturing or operational constraint, is a recurring purpose for the use of heuristic, gradient-based, or hybrid methods, the approach selected to do so differs significantly. The publications reviewed that used heuristic methods were more likely to optimize the ply-orientation considering a discrete set of values [12, 57, 73, 96, 112, 208]. On the other hand, researches using gradient-based or hybrid methods preferred continuous variables $[67,74,171,220]$, or the optimization of the lamination parameters followed by a second optimization or selection criteria to choose the stacking sequence with the most similar characteristics [60, 218]. This review does not have the extension of the work presented by Xu et al. [275] and Nikbakht et al. [174, 175], limiting the validity of a statistical analysis on the popularity of the different methods used in the literature. Nevertheless, in this sample, the GA and its variants (NSGA, or MIGA) were the most referred optimization method, which is in line with the reviews of Xu et al. [275] and Nikbakht et al. [174, 175].

\subsection{Topology optimization}

Topology optimization is one of the three sub-fields of structural optimization, amongst size and shape optimization, and is image cited from applied in the early stage of structural design. Its purpose is to find an optimal distribution of material $[6,163]$. The method defines a design region, divided into several finite elements, to be occupied by the structural component. According to an objective function, the optimization method adjusts the density of each element, defining which elements should have material and which should not [287].

The topology design approach has been applied to composite structures. However, the purpose of this combination is to allow the simultaneous definition of material distribution and fibre orientation. A simple procedure is to align the fibres in the direction of the first principal stress, as adopted by Fuchs et al. (1999) [84] and Ma et al. (2006) [144]. However, this approach consists of transforming a design variable into a constraint, rather than the optimization of both variables.

In 1999, Hansel and Becker [98] presented a layer-wise topology optimization that considered both material density and fibre orientation. In each layer, the material was removed in areas that either had low stress installed, or that had a fibre orientation that differed significantly from the principal stress direction. The removal was done by changing the density of the element to zero. According to the author, each "laminate element" is constituted by four layers with the common lay-up $\left[0^{\circ} / \pm 45^{\circ} / 90^{\circ}\right]$, referred to as "single-layer elements". Singlelayer elements that are not necessary for the load transfer are removed by reducing the layer thickness to zero. In later research [99], Hansel et al. (2002) applied this method to design a laminated composite cantilever plate and an L-shaped cantilever, using a GA to remove the unnecessary material.

To address the topology optimization of laminated com- posite plates, Stegmann and Lund proposed the gradient based method called Discrete Material Optimization (DMO), in 2005 [234]. The method is based on the idea of multiphase topology optimization, which does not select exclusively between the inclusion of material or voids, but between the inclusion of any distinct number of materials. The purpose is to find, for each element, one distinct material of the possible candidates such that the objective function is minimized. Stegmann and Lund applied this method to design a structure subject to a four-point bending test [234] and Niu et al. (2010) [177] to design a vibrating laminated composite plate for minimum sound radiation.

With the same purpose, Setoodeh et al. (2005) [216] developed a single criterion that simultaneously optimized the composite orientation and thickness of cantilever plates, minimizing the strain energy expressed in terms of fibre orientations and pseudo-densities. To do so, the authors extended the Solid Isotropic Material Penalization (SIMP) technique of topology design with a cellular automata (CA) framework. SIMP is a material interpolation scheme used in topology optimization that considers a continuous variable $\rho(0<p<1)$ that resembles the density of the material [24, 197]. The CA is a methodology used to simulate physical phenomenon based on iterative local updates of both field and design variables. During its functioning, the CA divides the domain of interest into several cells, which only interact with other adjacent cells, performing local computations [47]. Combining both SIMP and CA, the displacements of the structure were calculated and updated to satisfy local equilibrium of CA cells. Similarly, the fibre angles and density measures were updated based on the optimality criteria.

A different approach was proposed by Zhou and Li [292], in 2008, where the fibre orientations were determined by solving the minimum compliance problem and the densities by a resizing approach based on stress and strain energy. To avoid numerical instabilities, the approach did not remove elements with low density. Instead, after the algorithm had defined the orientation and density of the elements, the authors used a program that defined a truss-like structure based on the orientation of the fibres and on the densest areas of the structure. This second phase of the optimization process is image cited from referred to as a discrete material selection problem. For not removing material from the design volume, the authors deem it unsuitable for the topology optimization of structures with empty spaces, such as a plate with holes.

Gao and Duysinx (2012) [87] proposed a bi-value coding parametrization method, reducing the number of design variables. Instead of considering four different materials, with four design variables representing the density of each possible candidate material, the author considers two design variables with the possible values of -1 and 1 . In this case, the material to be attributed to each element is a result of the combination of the two design variables used, leading to a total of 4 possible combinations using only two design variables. These represent the number of candidate materials in a logarithmic form, which makes this approach efficient to deal with large-scale problems, as shown in [88]. 


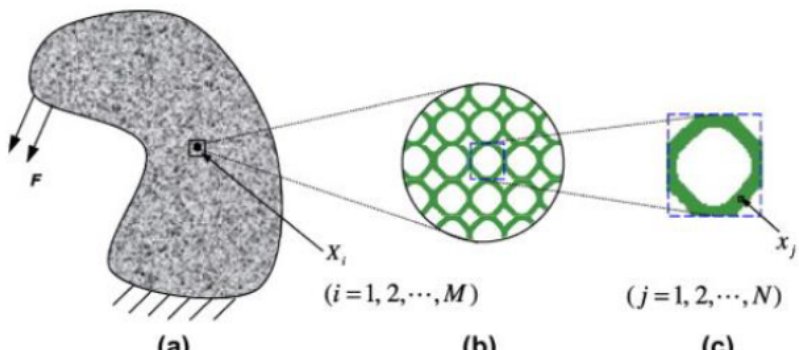

(a)

(b)

(c)

Figure 6: Macro-structure composed of cellular or composite materials: (a) macrostructure; (b) microstructure; (c) unit cell or RVE (image cited from [261]).

In 2013, Huang et al. [261] introduced a topology optimization algorithm capable of designing cellular materials and composites with periodic microstructures. The algorithm searches for the microstructure that maximizes the stiffness of the resulting macrostructure. The method is based on the bi-directional evolutionary structural optimization (BESO), which, unlike the evolutionary structural optimization (ESO), considers both the addition and removal of material to the structure [106, 274]. In its essence, the method proposed by Huang et al. considers a macro to micro-scale analysis and vice-versa, using two macro-scale and micro-scale finite elements models. The loads applied in the macro-scale are applied to an RVE whose phases are distributed using BESO (Figure 6 [261]). The properties of the new RVE are then used to estimate the behaviour of the structure at a macro-scale, aiming to maximize its stiffness [261]. Several case studies and a more detailed analysis of the application of this method was described by the same authors in [276], published one year later. The cases studied allowed the authors to conclude that there was a strong interaction between the two designs at both scales and that the two-scale optimization allowed a better design to be obtained due to the significant increase in the degrees of freedom.

Ren et al. (2016) [189] presented a topology optimization method for composite beams. The motivation for this work was the need to address various load cases characteristic of beams used in aircraft. The authors applied the finite element method to simulate the behaviour of the beam, considering warping and shear deformations. A multi-material optimization model was employed, considering the density of each candidate material at each element as the design variables. The updates of each design variable were done according to a sequential linear programming method. The authors state that the used approach led to a "checkerboard problem". This issue, detailed in [223], is overcome by applying a sensitivity filtering approach, which uses information regarding the neighbourhood of the element under evaluation.

A year later, Wang et al. (2017) [270] proposed a levelset topology optimization method (LSM) suitable for the optimization and design of metamaterials. The authors used a numerical homogenization method to evaluate the effective properties of the microstructure and a multiphase level-

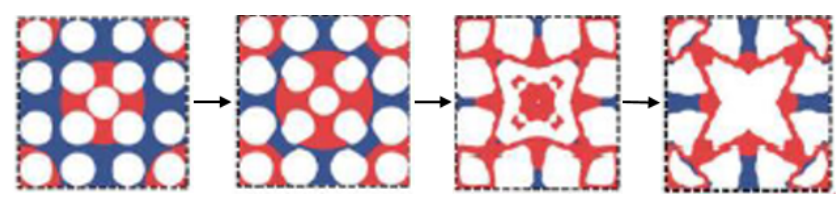

Figure 7: Convergence of the method towards a metamaterial with -0.5 Poisson's ratio (image cited from [270]).

set model to evolve the boundaries of the multimaterial microstructure. The level-set model was used to implicitly define the interfaces between the material phases by isocontours of a level-set function (LSF). Depending on the representation of the interface, the use of LSM may improve the accuracy with which the numerical model captures the mechanical response in the vicinity of the boundaries, thus avoiding ambiguities of intermediate material phases associated with the use of density-based approaches [252]. Using the multi-phase level-set model, Wang et al. [270] obtained a material geometry with distinct interfaces and smoothed boundaries that facilitate the fabrication of the topologically optimized design. Its application allowed the authors to define a microstructure with a negative Poisson's ratio and a negative coefficient of thermal expansion (Figure 7 [270]). Similar research was reported by Nishi et al. (2018) [176], following the same two-scale topology optimization approach. Likewise, Anaya et al. (2019) used a similar procedure but oriented towards the minimization of the effective thermal expansion coefficient of a composite material. The potential improvements obtained through the use of this approach is also supported by the results reported by Panesar et al. [180], who measured an improvement between $40 \%$ and $50 \%$ in terms of stiffness when using an approach that derives graded lattice structures from topology optimized solutions. Furthermore, the strategies identified by Panesar et al. also allow easier production of the structure through additive manufacturing.

Dai et al. (2017) [53] performed the topology optimization of a composite structure with design dependent loads. To do so, the authors proposed a methodology based on the isoline method, the sensitivity filter with density gradient weighting, and the solid isotropic material with penalization (SIMP) method. The work published reports successful results but is limited to a two-dimensional design.

Sousa et al. (2018) [230] analysed the design of multilayered composite laminates and the topological sensitivity in anisotropic elastistatics, considering the shape/topology of each ply and the stacking sequence as the design variables. To do so, the authors combined a topological sensitivity analysis and an ACO algorithm. The topological sensitivity analysis, based on the total potential energy of the system, provided information on the region where new material should be added. This information can be interpreted as a mapping of the different regions of the structure based on their contribution to the resistance of the component. Then, the ACO method was used to determine the orientation of the added material.

More recently, Tong et al. (2019) [248] applied a topol- 
ogy optimization method to design a composite compliant mechanism. This type of mechanism is characterized by its monolithic structure and for transmitting force, energy, and motion through self-deformation [105] (the reader is referred to [295] for a detailed review on the topology optimization of compliant mechanisms). Tong et al. designed compliant inverters and grippers, which are commonly used as benchmark problems. The authors predefined the lay-up thickness and the orientation of the composite laminate. The topology optimization was done considering the maximization of the deformation ability of the structure based on the stiffness penalization model. Furthermore, the authors reported that each update of the design variables was done considering a sensitivity analysis, evaluating its influence on the structural behaviour of the component by FEA. Zhu et al. (2019) [294] reported a similar research, differing on the use of the LSM and on the use of multi-objective optimization considering a symmetry constraint. In this case, the design volume was limited to the flexible region of the compliant mechanism and the multiple objectives are related to the combination of displacement and rigidity requirements.

Zhao et al. (2019) [291] performed the topology optimization of a compliant mechanism of a composite wing leading edge. The authors used the discrete material optimization method to distribute the multiphase composite material through the design volume. The objective of the optimization was to minimize the least square difference between the deformed curve of the wing and the desired aerodynamic shape. Despite the successful implementation and result, it was observed that the discrete material optimization presents a major drawback in the large number of design variables used, increasing the computational cost of the method.

Almeida et al. (2019) [7] proposed a methodology to optimize the cross-section of topologically-optimized variableaxial anisotropic composite structures, maximizing specific stiffness. The process relies on sequential optimizations of the topology using SIMP and then optimizations of the crosssection by means of a GA. The objective was to optimize the number of carbon fibre rovings to be placed at each truss section of a CFRP brake booster. During the topology optimization, an isotropic material is considered. The fibre orientation is defined according to the loading direction in the final topology. With this approach, the authors observed a $330 \%$ increase in stiffness of a brake booster system when compared to a commercially available solution.

Safonov (2019) [202] explored the use of topology optimization to design a structure reinforced with continuous fibre via a natural evolution method. The proposed method combined two techniques, simultaneously searching for density distribution and local reinforcement layup in 3D transversely isotropic composite structures. The direction of the reinforcement was aligned in each iteration, considering the direction of the principal stresses and the local minimum compliance, while the density distribution was optimized through a dynamical system method, which replaces the optimization problem by an ordinary differential equation whose equilibrium points coincide with the local optima [120]. When applied to the optimization of a simply supported $2 \mathrm{D}$ beam under central point load and to a 3D cantilever beam, the authors obtained a mass reduction of $66 \%$ and $90 \%$, respectively.

In the work published by Jong W. Lee et al. (2019) [130], the authors improved a stress-based topology optimization method for laminated composites through the application of the layer-wise theory. In this research, the stress constraint is set so that the composite does not exceed the Tsai-Hill failure criteria. To obtain information on the sensitivity of the stress to the element density and orientation, the authors used one of two types of p-norm stress approximations: one considering all composite layers and another considering a specific layer. The authors observed that the implementation of the proposed approach lead to designs that avoided stress concentration points, such as the corner of an L-bracket beam case study, and that the optimization of the laminate angles allowed a further reduction of the used material.

Jaewook Lee et al. (2018) [129] proposed a sequential three-step optimization procedure. The first step aims at finding the optimal topology design of matrix material when the FVF is set as zero. Then, the second step determines the optimal density distribution and continuous orientation of fibre material. The third step penalizes intermediate fibre orientations between target orientations, leading to a more discrete design. Lee et al. confirmed the advantage of the procedure by comparing the objective functional in the design results with evenly fixed and optimized target orientations. Furthermore, the authors confirmed that the approach could find the optimal layout of matrix and fibre rich regions in functionally graded composite structures through numerical examples.

Zhou et al. (2018) [293] proposed a topology optimization method that simultaneously modifies the topology and material orientation of multi-component composite structures. This approach considers the existence of $K$ components and three layers of design fields. The first layer contains the density field for all components, representing the density of each element. The second layer describes the inclusion of each design point into component $k$ (where $k=1,2, \ldots, K$ ). Finally, the third layer determines the material orientation of each component $k$, considering a continuous variation of the orientation angle as a function of the tension and material stiffness tensor field, for anisotropic materials. The reader is referred to Nomura et al. [178] for a detailed description of the material orientation process. Using a single load cantilever beam and a multi-load tandem bicycle frame as benchmark problems, Zhou et al. observed that the proposed method generated designs with better structural performance than conventional single-piece isotropic topology optimization methods and a continuous orientation method.

In the work of Jiang et al. (2019) [111], the authors report the use of a continuous fibre angle topology optimization method for polymer composite deposition additive manufacturing applications. The authors performed a compliance minimization optimization considering two design variables for each element: the element density and orientation. This parametrization is suitable for the problem as the structure 
is manufactured layer by layer, avoiding a three-dimensional orientation of the material and simplifying the parametrization of the problem. In [179], Nomura et al. (2019) present a different perspective on the material orientation initially proposed in 2015 [178]. This reformulated approach increased its versatility by introducing a different orientation parametrization and by removing underlying assumptions, while still aiming for a simultaneous optimization of the topology and material orientation. In this case, the orientation design variable is formulated as a tensor field, equivalent to a reduced version of the orientation tensor to represent a single direction at a point. This method avoids singular point issue that occur in the rotation-based approach (equivalence of angle 0 and $2 \pi$ radians) and ensures the unique correspondence between each tensor value and material property. Nomura $e t$ $a l$. observed clear performance advantages in both two and three-dimensional problems, as well as single and multi-load cases when compared to methods that define the topology first and then the material orientation.

Tong et al. (2019) [246, 247] performed the topology optimization of a composite laminate, as well as the optimization of the ply-angles considering the lamination parameters. This sensitivity-based approach is divided in two steps. In the first step, the lamination parameters and the density are set as the design variables, while the structural stiffness is parametrized by the lamination parameters. Minimizing the compliance with a volume constraint led to a final topology and to a set of lamination parameters that maximize the stiffness of the structure. Then, the orientation of the plies is retrieved by solving of a set of nonlinear equations. To solve this second problem, the authors transformed it into a least square optimization problem, finding the stacking sequence that best matches the initial lamination parameters.

Fu et al. (2019) [83] proposed a substructuring approach that allows the topology optimization on both macro and micro-scales. The microstructure of the material is optimized considering its own element volume constraint while minimizing the mean compliance of the macrostructure. The transition between the two scales is done through the homogenization of the material properties of the RVE, which are then introduced in the macro-scale FEA. A similar approach was proposed by Wu et al. (2019) [272] and Jansen and Pierard (2020) [109]. However, the authors used the multi-scale design approach to hierarchical lattice structures and functionally graded lattice structures, respectively. Regarding composite materials, Wu et al. (2020) [271] studied the robust concurrent topology optimization (CTO [42, 61, 138, 273]) of two-phase composite materials, using an improved hybrid perturbation analysis (IHPA) method to assess the worst performance of the structure under a random model based imprecise probability. More focused on fibre reinforced materials, Yan et al. (2019) [278] presented a CTO design method which optimizes the topology of the macrostructure, the material microstructure, and the material orientation. This twoscale approach is based on the BESO method and utilizes the information of the local principal stress direction to determine the orientation of the material in each element. Yan et al. observed that optimizing the topology and microstructure improved structural performance of the final design and that, image cited from, the resulting microstructure was anisotropic. In later research [277] Yan et al. extended the application of this method to three-dimensional case-studies, observing similar results. Gao et al. (2019) [85] and Li et al. (2019) [134] followed a similar procedure but applied the SIMP and LSM methods instead of BESO, respectively. Likewise, Zhang et al. (2020) [288-290] applied a multiscale method to find the optimal topology that minimizes the frequency response of a cellular composite within a given frequency range.

Focused on the definition of the material orientation, Silva et al. (2020) [224] revisited and modified the normal distribution fibre optimization (NDFO) method. Therefore, the values of angles are inserted directly into a normal distribution function and the output is modified with a Helmholtz filter, ensuring the continuity of the fibres. This modification allowed the lifting of some restrictions, such as imposing small strains, displacements, and rotations, and consequently expanding the range of application of this approach.

In the current state of the art, it is possible to observe an evolution of the topology optimization methods applied to composite materials. The focal point of research in this area has been the inclusion of design variables and their efficient management. From a physical perspective, this means the addition of material properties, such as the strength of the material [130], the orientation of the fibre reinforcements [87, 98, 99, 130, 178, 179, 202, 216, 224, 230, 248, 292, 293], lamination parameters [246, 247] or information on the microstructure of the composite and its influence on a macro-scale level $[13,83,85,109,134,176,261,270,272,276-278,288-$ 290], the inclusion of multiple materials [177, 234, 291], and manufacturing or process constraints [111]. A topic of research scarcely explored is the inclusion of fracture or damage predictive models in the topology optimization of composites, only referred in [130] where the authors used the Tsai-Hill failure criteria, which was imposed as a maximum stress constraint. In research not restricted to composite materials, the inclusion of damage tolerance or damage predictive models, in the topology optimization process, has already been under investigation since 1998 [4, 22]. The combination of these concepts has been used as a conservative approach, leading to designs with multiple load paths that enable a structure to function in the presence of damage [66].

\subsection{Damage tolerance}

The existence of defects in composite materials, either resulting from the manufacturing process or due to loads applied during operation, can cause changes in the performance of the structure. Regardless of the motivation being the search for an increased performance and/or safety factor, or simply to avoid costs associated with maintenance and discard of components, the study of the damage tolerance of materials has been a subject of research for many years $[6,162]$. This concept defines the ability of a structure to sustain a determined level of fatigue, corrosion, or impact damage able to 
be detected and repaired. Traditionally, the damage tolerance of metallic structures is governed by damage resulting from fatigue and crack propagation [286].

Whether the distinction between the relevant sources of damage that is more harmful to each type of material is correct or not, it is expected that the exposure to operating conditions and external factors promotes the initiation, accumulation and propagation of damage [6]. This has led researchers to perform an extensive research on the influence of different load cases and external conditions on the damage tolerance of composite materials, such as: the influence of fabric architecture and resin toughness on the impact resistance $([69,82,93,100,101,192,215,250,280]$ and $[18-20,100,101,115,137,209,228,243,250]$, respectively) and damage tolerance ([40, 46, 91, 100, 101, 185] and $[35,86,190,227,228,254]$, respectively) of CFRP, the effect of fracture toughness $[1,82,115,136,222,240,241$, $243,280]$, repeated impact $[15,17,107,117,210,211]$, impact geometry [8, 16, 27, 34, 76, 90, 108, 116, 165, 217], stacking sequence $[3,18,68,142,207,262]$, environmental conditions [143, 160, 199, 200, 229, 259, 260, 263] including radiation $[92,145,146,164]$, and fabric $[19,20,68,212]$ or matrix hybridization $[25,172,201,212,226,263]$ on the damage tolerance of the material.

The extensive research performed throughout the years has supported several industries, promoting the adoption of damage tolerance concepts in the design of multiple structures. Braga et al. (2014) [29] reviewed and discussed possible future prospects of the major design philosophies that have been employed in aircraft structures, including damage tolerance. In this sector, the concept of damage tolerance introduced the assumption that an initial structural damage exists in the structure, making it a requirement that needs to be considered. The objective of this assumption was to determine inspection thresholds and intervals. To do so, fracture mechanics evaluations of crack growth and residual strength characteristics were coupled with damage detection assessments. The data obtained from service-based crack detection procedures, combined with the residual strength and fatigue crack growth data, is used to define detection reliability ratings, considering multiple types of inspections. The definition of the inspection thresholds and intervals promoted the focus of research on non-destructive inspection (NDI) techniques, such as: dye penetrant inspection, magnetic particle inspection, radiography, ultrasonic inspection, Eddy currents, thermal imaging, and digital image correlation (DIC).

In 2015, McGugan et al. [162] proposed a design and maintenance methodology to be applied in wind turbine rotor blades, assuming that either it is not possible to manufacture a perfect structure, or that discarding or repairing defects in a structure is too costly. Besides the use of a structural health monitoring system (SHM) to assess the state of the structure, one of the key aspects of the design method proposed was the inclusion of a damage tolerance index, coupling the materials and the structure. This methodology requires the use of materials whose strength is significantly higher than the linear-elastic limit, to allow an easy detection of the dam- age and enabling the possibility of repairing or replacing the damaged part. Similarly, Yue et al. [285] proposed a design philosophy that is based on the structural health monitoring and associated testing at different levels of complexity, starting from a coupon level. According to the authors, using the information obtained through the analysis of previous levels, it is possible to detect multiple barely visible impact damage in large composite panels by outlier analysis using a reference pristine database gathered from simple coupons. From a more general point of view, this bottom up approach of increasing complexity provides valuable knowledge that will more accurately predict the health status of the design component.

The interest of the industry in this concept, combined with the limitations of the analytical solutions available, promoted the research and development of numerical tools capable of predicting the damage initiation and propagation in a structure after a certain loading condition. Damage modelling can be divided into four categories: failure criteria based, continuum damage mechanics-based, fracture mechanics-based, and plasticity or yield-surface based models. Failure criteriabased models use polynomial expressions to define a failure envelope that indicates the initiation of damage as a function of the stress or strain installed. However, it does not include information regarding the position, size, and progression of the crack. Fracture mechanics addressed this issue through the inclusion of information regarding the energy required to create and propagate a crack. In turn, fracture mechanics require information regarding the initial flaw. In composite materials, the prediction of progressive damage can be achieved through the combination of these two methods. For ductile composites, this approach can be complemented with plasticity-based damage models [219].

So far, this rather extended introduction summarizes the motivation, design philosophies, and modelling approaches associated with damage tolerance. Over the last decade, the prediction of the damage tolerance is a topic of significant research interest. However, simulating residual strength tests is quite challenging. Gonzalez et al. (2012) [91] simulated the low-velocity impact and the compression after impact (CAI) tests, using both interlaminar and intralaminar (LaRC04 failure criteria $[58,183])$ damage models. This extremely expensive computational model predicted the residual strength with a $20 \%$ error, resulting from the comparison between numerical and experimental results.

Rivallant et al. (2013) [193] and Hongkarnjanakul et al. (2013) [103] successfully captured the permanent indentation resulting from a CAI test, as well as the crack propagation and buckling of sub laminates due to the impact. The simulations were an improved version of the model proposed by Bouvet, et al (2012) [28], considering the failure of fibres under compressive loads.

Camanho et al. (2015) [36], proposed a three-dimensional failure criterion for CFRP based on structural tensors. The criteria for the transverse failure was formulated from the invariant theory, while the tensile fracture in the fibre direction is predicted using the maximum strain criterion. A 
three-dimensional kinking model was used to predict the longitudinal compressive failure, capable of accounting for the nonlinear shear response. The criterion was proved both accurate and useful in the validation of failure under complex three-dimensional stress states.

Tan et al. (2015) [242] proposed a nonlinear shear-based damage model. In their research, the authors aimed to predict the compressive residual strength of the composite through the coupling of the matrix tensile failure criteria proposed by Puck and Schurmann (2004) [186] and the compressive failure criteria proposed by Catalanotti et al. (2013) [39]. A three-step process was used to simulate the low-velocity impact, stabilization of the specimen and update of the boundary conditions, and the CAI analysis. The results report a high accuracy in the residual strength predicted and successfully captured the permanent indentations.

Caputo et al. (2015) [38] simulated a low-velocity impact and CAI test in ABAQUS ${ }^{\circledR}$ [157]. Using a single step analysis allowed the authors to consider the effect of impact damage distribution as the starting configuration of the CAI test. Through this methodology, the authors were able to predict the interlaminar and intralaminar damage with a $9 \%$ accuracy. Elias et. Al (2017) [71] divided this method in a two-step process. The purpose of this division was to execute the low-velocity impact first, to obtain the damage pattern, including indentation depth and damage area, as well as the damage indices on each element. The second step focuses on estimating the residual strength. The results further support an accurate prediction of the damage mechanisms.

A simplified approach to predict CAI strength in laminated composites was proposed by Rozylo et al. (2017) [198]. In this research, a relationship between the thickness of the plies and the impact energies was established. A progressive damage criterion describing initiation of damage according to the Hashin model was used, while the propagation was determined using the established energy model. The numerical results were in good agreement with the experimental data reported by Tan et al. (2015) [242].

Abir et al (2017) [1] adopted the single step approach using Tsai-Wu failure criteria for damage initiation. The authors observed that local buckling and delamination growth caused the failure of the composite under CAI. A high influence of the Mode II interlaminar and fibre compressive fracture toughness was also observed, whose increase reduced the delamination size and improved the damage tolerance.

In 2018, Cugnoni et al. [50] performed an extensive experimental testing campaign, addressing the influence of ply thickness, fibre, matrix, and interlayer toughening on strength and damage tolerance. The detailed characterization allowed the authors to obtain a master curve diagram, modelling the reduced in-situ strength of the composite as a function of the ply thickness. This master curve was further expanded for larger values of thickness using the models proposed by Dvorak and Laws (1987) [70], and later extended by Camanho et al. (2006) [37]. The master curve obtained is overall conservative and suitable for first order estimates.

Liu et al. (2018) [137] presented a numerical model to simulate the CAI of hybrid unidirectional or woven CFRP laminates. Through a user defined material subroutine in ABAQUS $^{\circledR}$ [157], the authors implemented a three-dimensional damage model based on continuum damage mechanics and linear elastic fracture mechanics. The model considered interlaminar and intralaminar damage, load reversal, and nonlinear shear profiles to account for matrix plasticity. The experimental results agreed with the numerical predictions, with the numerical model capturing the behaviour of the composite under compressive loading.

Recent research has studied the possibility of improving the damage tolerance through novel materials. To improve the resistance of composite laminates to delamination when subjected to impact loadings, Daelemans et al. (2019) [51] studied the influence of electrospun nanofibers on the occurrence of delamination failure in composites. An increase of $60 \%$ of the delamination resistance under both Modes I and II was estimated. Dimoka et al. (2019) [65] have also investigated the influence of nanomaterials in the damage tolerance of a CFRP laminate reinforced with multi-walled carbon nanotubes (MWCNTs) subject to low-velocity impact and then tested under compression loads. The results revealed an improved performance in the residual compressive strength after impact when compared to the non-modified CFRP. For impact tests with high energy levels (30 J), an increase in the delamination area was observed. However, the opposite phenomenon was observed for impact energy levels of $8 \mathrm{~J}$ and $15 \mathrm{~J}$.

Tie et al. (2020) [245] maximized the impact-resistance of a patch repaired CFRP laminate using a surrogate-based model based on the Diffuse Approximation and Design of Experiments, which obtained information from FEM of patchrepaired CFRP laminates that consider continuum damage mechanics (CDM) and cohesive zone modelling (CZM). The outcome observed by Tie et al. was a significant increase of the impact-resistance, decreasing the impact energy absorption and the delamination surface area.

On the use of these numerical models towards the design of composite structures, Sellitto et al. (2020) [214] applied a GA to optimize the stacking sequence of an aeronautical stiffened panel. The optimization had two objectives: maximizing the buckling load and minimizing the weight among the configurations capable of withstanding a low velocity impact. The authors considered four possible ply orientations $\left[0^{\circ},+45^{\circ},-45^{\circ}, 90^{\circ}\right]$ and applied a linear damage criterion to assess the structural integrity of each configuration. This approach led to two possible configurations that minimize the number of plies of the panel and maximize the buckling load. Similarly, Reddy et al. (2020) [188] developed an enhanced bat algorithm (EBA) and used it to optimize the number of plies and their orientation. The objective was the weight minimization of the laminate, constrained by the initiation of damage according to the Tsai-Wu failure criterion.

Particularly concerned with the buckling and post-buckling behaviour of thin-walled composite laminated beams and columns, Mittelstedt (2020) [166] reported and extensive literature research on the topic. Mittelstedt has observed that 
almost all theoretical approaches toward the constitutive modelling and global-local buckling analysis rely on either classical laminated plate theory or first-order shear deformation theory, contrasting with the often need of using higher-order shear deformation theory for composite laminated materials. Furthermore, Mittelstedt identifies the need for further investigation on the influence of delamination on the static performance, buckling resistance, buckling and post-buckling behaviour of thin-walled composite beams. The author also suggests further investigation on progressive failure analysis, studying composite beams in the post-buckling considering damage accumulation models. For a more detailed analysis on each of these topics, the interested reader is referred to [166].

A first special mention is given to Fedulov and Fedorenko (2020) [81], for combining topology optimization concepts with the analysis of damage propagation in a composite material. The authors proposed a method based on the inverse approach of a standard compliance minimization topology optimization problem to estimate the residual strength of a laminated composite with barely visible impact damage. In other words, the energy transmitted by a given impact is distributed in the composite material through a sensitivity analysis, maximizing the compliance of the structure. This energy is then used to degrade the material properties of the composite according to a progressive degradation material model. A good correlation between predicted and experimental results was observed.

A second, and final, special mention is given to the study of imperfections in the design of deployable structures. As stated by Chen et al., kinematic singularity can frequently exist in deployable structures, especially when adjacent links become coplanar, affecting the accuracy, deployment performance and structural stiffness [44]. Addressing mechanisms on a more general level, of which deployable structures are part of, Lengyel and You [131] have demonstrated that the bifurcations of several mechanisms correspond to various catastrophe germs, highlighting the influence of imperfections on the behaviour of the mechanism. An interesting approach is taken by Steinboeck et al. [235], who investigated the necessary and/or sufficient conditions to achieve an imperfection insensitive system based on Koiter's initial post-buckling analysis [121]. Since kinematic bifurcation is generally unavoidable for deployable structures, Chen $e t$ al. [43] follow a different route, proposing a methodology that decomposes the compatibility matrix of a deployable structure and extracts new mechanism modes with lower-order symmetries associated with independent bifurcation paths. Then, a prediction-correction algorithm is used, leading the structure into the expected bifurcation paths.

Through the review of the state of the art, it is possible to infer that the concept of damage tolerance is relevant for several industries. This interest has led to extensive research on the influence of external factors and loads on the damage tolerance of materials, the simulation of damage initiation and propagation, and the prediction of residual properties. More recently, the development of new materials has promoted the study and research of the influence of nanomaterials on the damage tolerance of the modified structure. However, the vast majority of these investigations are focused on the development or improvement of existing tools in order to allow an accurate prediction of the damage incurred in a given operating condition, with only a few recent articles actively using this information in the design of a composite structure [77, 80, 150, 188, 214, 233, 245].

\section{Final remarks on the design and optimization of self-deployable damage tolerant composite structure}

The present review explores the possibility of increasing the performance of a composite self-deployable structure through the allowance of damage initiation during operation. The use of a damage tolerant structure is identified as a possible solution to meet highly demanding design requirements identified by the ESA for self-deployable telecommunication satellites [72]: achieving a design that is, simultaneously, flexible to fold in the elastic regime, but also rigid enough to reach high natural frequencies. Opting for a damage tolerant design, and relaxing the need for the structure to operate in the elastic regime, is seen as a potential solution to reaching the required natural frequency of vibration through the increase of the stiffness of the structure previously limited by the requirement of an elastic design.

The proposal of a damage tolerant design is justified by two particularities of this application. The first, is the lifecycle of the structure, as most deployable systems are expected to perform a single deployment operation once in orbit. While imposing the functioning of the deployable system in the elastic regime does lead to a higher safety factor, it also implies a significant over-design of the structure and, in this case, limits the maximum stiffness and its resulting natural frequency. The second, is the expected life-time of a satellite. Apart from their size and cost, the development of nanosatellites and CubeSats is also motivated by their reduced development time. Average or large-sized satellites require between 5 and 15 years to place in orbit under normal parameters, incurring the risk of no longer being market-relevant due to the pace of technological progress. In contrast, CubeSats and nano-satellites require less than 8 months to place in orbit. This trend towards a shorter development time allows a frequent renewal, guarantees the robustness of nano-satellite constellations, and removes the need for a conservative longterm design [21, 32, 52, 95]. However, it is important to acknowledge a potential downside of using a damage tolerant design in this application, which is the possible release of debris when the initiation of damage occurs. This phenomenon can be overcome with the inclusion of containing systems, similar to a membrane that covers the elastic-hinge. Therefore, small debris will no longer be considered as a limiting factor to the exploration of this concept.

Three research topics were surveyed to look for a suitable design methodology that could lead to a composite selfdeployable damage tolerant design. These research topics 
Table 2

Number of publications on the subject of composite structures design sorted by the methodology and use, or not, of damage tolerance.

\begin{tabular}{|c|c|c|c|c|c|c|}
\hline \multirow{3}{*}{$\begin{array}{c}\text { Composite structure } \\
\text { type }\end{array}$} & \multirow{3}{*}{$\begin{array}{l}\text { Damage } \\
\text { tolerance }\end{array}$} & \multicolumn{5}{|c|}{ Design approach } \\
\hline & & \multirow{2}{*}{ Analytical } & \multicolumn{3}{|c|}{ Numerical } & \multirow{2}{*}{$\begin{array}{c}\text { Topology } \\
\text { Optimization }\end{array}$} \\
\hline & & & Heuristic & Gradient-based & Hybrid & \\
\hline \multirow{2}{*}{ Elastic-hinge } & Without & 2 & 11 & 4 & 1 & 1 \\
\hline & With & 0 & 0 & 0 & 0 & 0 \\
\hline \multirow{2}{*}{ Others } & Without & 1 & 8 & 9 & 7 & 48 \\
\hline & With & 0 & 3 & 1 & 2 & 1 \\
\hline
\end{tabular}

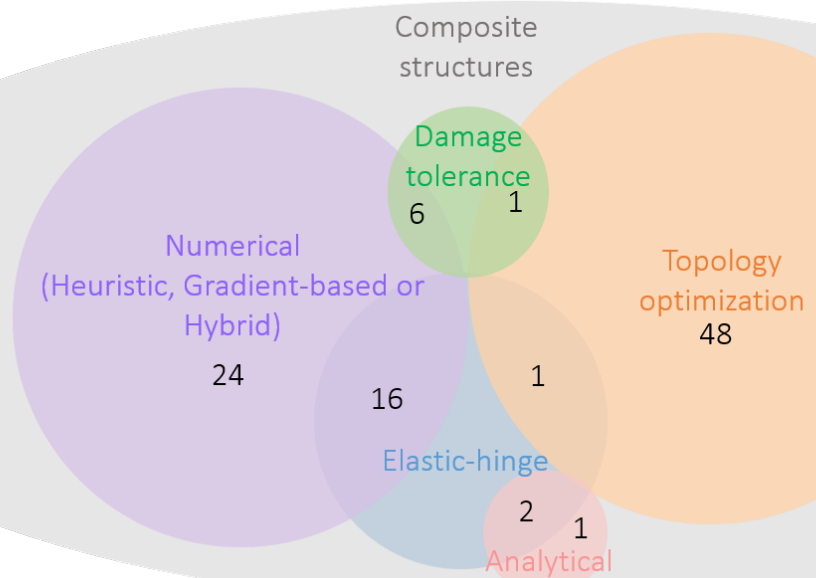

Figure 8: Venn diagram showing the number of publications on the subject of composite structures design sorted by the methodology and use, or not, of damage tolerance.

included: the design of deployable structures (section 2), the design of composite structures (section 3.1), and the use of damage tolerance in composite structures (section 3.3).

The survey of the design approaches applied to deployable structures allowed the observation of a clear evolution from the use of analytical methods [232, 233] towards the use of numerical approaches combined with optimization algorithms [48, 62, 77, 80, 110, 203-206, 269, 279]. The design tools changed and stress [150] and strain-based [149] criteria were developed specifically for materials used in deployable systems. However, the same conservative design philosophy was maintained across all researches: ensuring the functioning of the deployable system in the elastic regime.

Comparing the design methodologies used for deployable structures with methodologies used for other composite structures, it is possible to identify similarities in the heuristic, gradient-based, and hybrid methods. In all cases, it is common for the design process to involve the optimization of the stacking sequence of the laminate, considering either a discrete or continuous ply-angle variation, respectively, and the optimization of several geometrical variables. The only difference noticed was the optimization of the lamination parameters, which was not observed when designing deployable structures, probably due to the fewer number of publications about composite self-deployable structures.

On the other hand, the popularity of using topology optimization is significantly different. Only one research [80] ex- plored the use of this approach to design an elastic-hinge. In other fields of application, the topology optimization of composite materials has evolved significantly, in particular regarding the efficient inclusion of additional material properties such as the strength of the material [130], the orientation of the fibre reinforcements $[87,98,99,130,178,179,202,216$, 224, 230, 248, 292, 293], lamination parameters [246, 247] or information of the microstructure of the composite and its influence on a macro-scale level [13, 83, 85, 109, 134, 176, 261, 270, 272, 276-278, 288-290], the inclusion of multiple materials [177, 234, 291], and manufacturing or process constraints [111].

Once again, the inclusion of fracture or damage predictive models in the topology optimization of composite materials is scarcely addressed [130]. This observation was unexpected. In research not related to composite materials, this has been a topic of research since 1998 [4, 22] and the outputs have been relevant in several industries $[6,162]$. Regarding composite materials, the capability to predict the initiation and propagation of damage in composite materials, as well as to estimate the residual properties has been extensively explored $[1,3,8,15-20,25,27,34,35,40,46,68,69,76$, $82,86,90,91,93,100,101,107,108,115-117,136,137$, $142,143,160,165,172,185,190,192,199-201,207,209-$ $212,215,217,222,226-229,240,241,243,250,254,259$, $260,262,263,280]$ and is particularly relevant in industries such as aeronautics $[59,268]$, where this information 
can be useful to ensure the functioning of the structure in anomalous conditions. However, only a few recent articles actively use this information in the design of a composite structure [77, 80, 150, 188, 214, 233, 245].

In summary, these surveys allowed the identification of several research topics that have not been addressed in the literature (highlighted in Table 2 and Figure 8). The use of topology optimization coupled with damage has either been rarely or never used in the design of self-deployable composite structures. The extensive research of these concepts in other areas indicates that these approaches have reached a relevant maturity level that could justify their application to this particular scenario. Furthermore, no limiting factors that could exclude the use of these concepts in the design of self-deployable composite structures were identified. Considering this information, the authors suggest the modification of a stress-constraint topology optimization approach to consider the maximum index of failure resulting from composite failure criterion, the energy dissipated through material degradation, or a maximum area of damaged material as a possible approach to consider damage tolerance in the topology optimization of a self-deployable composite structure.

\section{Acknowledgements}

P. Fernandes gratefully acknowledges the financial support from FCT - Fundação para a Ciência e a Tecnologia, I.P., under the scope of the Ph.D. Grant SFRH/BD/145425/2019, co-financed by the European Social Fund through NORTE 2020 .

\section{References}

[1] Abir, M.R., Tay, T.E., Ridha, M., Lee, H.P., 2017. Modelling damage growth in composites subjected to impact and compression after impact. Composite Structures 168, 13-25. doi:10.1016/ j.compstruct.2017.02.018.

[2] Abramovich, H., 2017. Introduction to composite materials. CRC Press. doi:10.1016/B978-0-08-100410-4.00001-6.

[3] Agrawal, S., Singh, K.K., Sarkar, P.K., 2014. Impact damage on fibre-reinforced polymer matrix composite - A review. Journal of Composite Materials 48, 317-332. doi:10.1177/0021998312472217.

[4] Akgün, M.A., Haftka, R.T., 2000. Damage tolerant topology optimization under multiple load cases. 41st Structures, Structural Dynamics, and Materials Conference and Exhibit, 317doi:10.2514/ 6.2000-1389.

[5] Albanesi, A.E., Peralta, I., Bre, F., Storti, B.A., Fachinotti, V.D., 2020. An optimization method based on the evolutionary and topology approaches to reduce the mass of composite wind turbine blades. Structural and Multidisciplinary Optimization , 125doi:10.1007/s00158-020-02518-2.

[6] Alderliesten, R.C., 2015. Designing for damage tolerance in aerospace: A hybrid material technology. Materials and Design 66, 421-428. doi:10.1016/j.matdes.2014.06.068.

[7] Almeida, J.H.S., Bittrich, L., Nomura, T., Spickenheuer, A., 2019. Cross-section optimization of topologically-optimized variableaxial anisotropic composite structures. Composite Structures 225, 111150. URL: http://www.sciencedirect.com/science/article/pii/ S0263822319304751, doi:10.1016/j.compstruct.2019.111150.

[8] Ambur, D.R., Kemmerly, H.L., $1998 . \quad$ Influence of impactor mass on the damage characteristics and failure strength of laminated composite plates, in: Collection of Technical Papers -
AIAA/ASME/ASCE/AHS/ASC Structures, Structural Dynamics and Materials Conference, pp. 724-732. doi:10.2514/6.1998-1784.

[9] Amendola, A., Hernández-Nava, E., Goodall, R., Todd, I., Skelton, R.E., Fraternali, F., 2015. On the additive manufacturing, posttensioning and testing of bi-material tensegrity structures. Composite Structures 131, 66-71.

[10] An, H., Chen, S., Huang, H., 2015a. Improved Genetic Algorithm with Two-Level Approximation Method for Laminate Stacking Sequence Optimization by Considering Engineering Requirements. Mathematical Problems in Engineering 2015. doi:10.1155/ 2015/595484.

[11] An, H., Chen, S., Huang, H., 2015b. Laminate stacking sequence optimization with strength constraints using two-level approximations and adaptive genetic algorithm. Structural and Multidisciplinary Optimization 51, 903-918. doi:10.1007/s00158-014-1181-0.

[12] An, H., Chen, S., Huang, H., 2019. Stacking sequence optimization and blending design of laminated composite structures. Structural and Multidisciplinary Optimization 59, 1-19. URL: https://doi.org/ 10.1007/s00158-018-2158-1, doi:10.1007/s00158-018-2158-1.

[13] Anaya, L., Vicente, W., Pavanello, R., 2019. Minimization of the Effective Thermal Expansion Coefficient of Composite Material Using a Multi-scale Topology Optimization Method, in: Rodrigues, H.C., Herskovits, J., Mota Soares, C.M., Araújo, A.L., Guedes, J.M., Folgado, J.O., Moleiro, F., Madeira, J.F.A. (Eds.), EngOpt 2018 Proceedings of the 6th International Conference on Engineering Optimization, Springer International Publishing, Cham. pp. 1055-1060. doi:10.1007/978-3-319-97773-7.

[14] António, C.A.C., 1995. Optimization of structures using composite materials made of polymeric matrix.

[15] Arikan, V., Sayman, O., 2015. Comparative study on repeated impact response of E-glass fiber reinforced polypropylene \& epoxy matrix composites. Composites Part B: Engineering 83, 1-6. doi:10.1016/ j.compositesb.2015.08.051.

[16] Artero-Guerrero, J.A., Pernas-Sánchez, J., López-Puente, J., Varas, D., 2015. Experimental study of the impactor mass effect on the low velocity impact of carbon/epoxy woven laminates. Composite Structures 133, 774-781. doi:10.1016/j.compstruct.2015.08.027.

[17] Atas, C., Dogan, A., 2015. An experimental investigation on the repeated impact response of glass/epoxy composites subjected to thermal ageing. Composites Part B: Engineering 75, 127-134. doi:10.1016/j.compositesb.2015.01.032.

[18] Bandaru, A.K., Ahmad, S., Bhatnagar, N., 2017. Ballistic performance of hybrid thermoplastic composite armors reinforced with Kevlar and basalt fabrics. Composites Part A: Applied Science and Manufacturing 97, 151-165. doi:10.1016/j.compositesa.2016.12.007.

[19] Bandaru, A.K., Chavan, V.V., Ahmad, S., Alagirusamy, R., Bhatnagar, N., 2016a. Low velocity impact response of 2D and 3D Kevlar/polypropylene composites. International Journal of Impact Engineering 93, 136-143. doi:10.1016/j.ijimpeng.2016.02.016.

[20] Bandaru, A.K., Patel, S., Sachan, Y., Alagirusamy, R., Bhatnagar, N., Ahmad, S., 2016b. Low velocity impact response of 3D angleinterlock Kevlar/basalt reinforced polypropylene composites. Materials and Design 105, 323-332. doi:10.1016/j.matdes.2016.05.075.

[21] Bandyopadhyay, S., Foust, R., Subramanian, G.P., Chung, S.J., Hadaegh, F.Y., 2016. Review of formation flying and constellation missions using nanosatellites. Journal of Spacecraft and Rockets 53, 567-578.

[22] Bendsøe, M.P., Díaz, A.R., 1998. A method for treating damage related criteria in optimal topology design of continuum structures. Structural Optimization 16, 108-115. doi:10.1007/s001580050011.

[23] Bendsøe, M.P., Kikuchi, N., 1988. Generating optimal topologies in structural design using a homogenization method. Computer Methods in Applied Mechanics and Engineering 71, 197-224. doi:10.1016/ 0045-7825 (88/90086-2.

[24] Bendsøe, M.P., Sigmund, O., 1999. Material interpolation schemes in topology optimization. Archive of Applied Mechanics 69, 635-654. doi:10.1007/s004190050248.

[25] Boccardi, S., Meola, C., Carlomagno, G.M., Sorrentino, L., Sime- 
oli, G., Russo, P., 2016. Effects of interface strength gradation on impact damage mechanisms in polypropylene/woven glass fabric composites. Composites Part B: Engineering 90, 179-187. doi:10.1016/j.compositesb.2015.12.004.

[26] Boesch, C., Pereira, C., John, R., Schmidt, T., Seifart, K., Lautier, J.M., 2007. Ultra light self-motorized mechanism for deployment of light weight reflector antennas and appendages, in: European Space Agency, (Special Publication) ESA SP, Citeseer. pp. 7-9.

[27] Boria, S., Scattina, A., Belingardi, G., 2017. Impact behavior of a fully thermoplastic composite. Composite Structures 167, 63-75. doi:10.1016/j.compstruct.2017.01.083.

[28] Bouvet, C., Rivallant, S., Barrau, J.J., 2012. Low velocity impact modeling in composite laminates capturing permanent indentation. Composites Science and Technology 72, 1977-1988. doi:10.1016/ j.compscitech.2012.08.019.

[29] Braga, D.F., Tavares, S.M., Da Silva, L.F., Moreira, P.M., De Castro, P.M., 2014. Advanced design for lightweight structures: Review and prospects. Progress in Aerospace Sciences 69, 29-39. doi:10.1016/ j.paerosci.2014.03.003.

[30] Brinkmeyer, A., Pellegrino, S., Weaver, P.M., Santer, M., 2013 a. Effects of viscoelasticity on the deployment of bistable tape springs, in: ICCM International Conferences on Composite Materials, pp. 370-380.

[31] Brinkmeyer, A., Pellegrino, S., Weaver, P.M., Santer, M., $2013 \mathrm{~b}$. Effects of viscoelasticity on the deployment of bistable tape springs. ICCM International Conferences on Composite Materials 2013-July, 370-380.

[32] Brown, O., Eremenko, P., Collopy, P., 2009. Value-centric design methodologies for fractionated spacecraft: Progress summary from Phase I of the DARPA System F6 Program, in: AIAA Space 2009 Conference \& Exposition, p. 6540.

[33] Brush, D.O., Almroth, B.O., Hutchinson, J.W., 1975. Buckling of Bars, Plates, and Shells. Journal of Applied Mechanics 42, 911-911. doi: $10.1115 / 1.3423755$.

[34] Bucinell, R., Nuismer, R., Koury, J., 2009. Response of Composite Plates to Quasi-Static Impact Events, in: Composite Materials: Fatigue and Fracture (Third Volume). ASTM International, pp. 528528-22. doi:10.1520/stp17735s.

[35] Bull, D.J., Spearing, S.M., Sinclair, I., 2014. Observations of damage development from compression-after-impact experiments using ex situ micro-focus computed tomography. Composites Science and Technology 97, 106-114. doi:10.1016/j.compscitech.2014.04.008.

[36] Camanho, P.P., Arteiro, A., Melro, A.R., Catalanotti, G., Vogler, M., 2015. Three-dimensional invariant-based failure criteria for fibrereinforced composites. International Journal of Solids and Structures 55, 92-107.

[37] Camanho, P.P., Dávila, C.G., Pinho, S.T., Iannucci, L., Robinson, P., 2006. Prediction of in situ strengths and matrix cracking in composites under transverse tension and in-plane shear. Composites Part A: Applied Science and Manufacturing 37, 165-176. doi:10.1016/j.compositesa.2005.04.023.

[38] Caputo, F., De Luca, A., Sepe, R., 2015. Numerical study of the structural behaviour of impacted composite laminates subjected to compression load. Composites Part B: Engineering 79, 456-465. doi:10.1016/j.compositesb.2015.05.007.

[39] Catalanotti, G., Camanho, P.P., Marques, A.T., 2013. Threedimensional failure criteria for fiber-reinforced laminates. Composite Structures 95, 63-79.

[40] Chen, F., Hodgkinson, J.M., 2009. Impact behaviour of composites with different fibre architecture. Proceedings of the Institution of Mechanical Engineers, Part G: Journal of Aerospace Engineering 223, 1009-1017. doi:10.1243/09544100JAERO451.

[41] Chen, S., Lin, Z., An, H., Huang, H., Kong, C., 2013. Stacking sequence optimization with genetic algorithm using a two-level approximation. Structural and Multidisciplinary Optimization 48, 795-805. doi:10.1007/s00158-013-0927-4.

[42] Chen, W., Tong, L., Liu, S., 2017. Concurrent topology design of structure and material using a two-scale topology opti- mization. Computers and Structures 178, 119-128. doi:10.1016/ j.compstruc.2016.10.013.

[43] Chen, Y., Feng, J., Sun, Q., 2018. Lower-order symmetric mechanism modes and bifurcation behavior of deployable bar structures with cyclic symmetry. International Journal of Solids and Structures 139, $1-14$.

[44] Chen, Y., Yan, J., Feng, J., 2019. Mechanism Design with Singularity Avoidance of Crystal-Inspired Deployable Structures. Crystals 9, 421.

[45] Chen, Y., Yan, J., Sareh, P., Feng, J., 2020. Feasible prestress modes for cable-strut structures with multiple self-stress states using particle swarm optimization. Journal of Computing in Civil Engineering 34, 4020003.

[46] Chiu, C.H., Lai, M.H., Wu, G.M., 2004. Compression failure mechanisms of 3-D angle interlock woven composites subjected to lowenergy impact. Polymers and Polymer Composites 12, 309-320. doi:10.1177/096739110401200405.

[47] Chopard, B., 2012. Cellular automata modeling of physical systems. volume 9781461418. Springer. doi:10.1007/978-1-4614-1800-9.

[48] Chu, Z.Y., Lei, Y., 2014. Design theory and dynamic analysis of a deployable boom. Mechanism and Machine Theory 71, 126-141. doi:10.1016/j.mechmachtheory.2013.09.009.

[49] Cook, A.J., Walker, S.J., 2016. Experimental research on tape spring supported space inflatable structures. Acta Astronautica 118, 316328. doi:10.1016/j.actaastro.2015.10.016.

[50] Cugnoni, J., Amacher, R., Kohler, S., Brunner, J., Kramer, E., Dransfeld, C., Smith, W., Scobbie, K., Sorensen, L., Botsis, J., 2018. Towards aerospace grade thin-ply composites: Effect of ply thickness, fibre, matrix and interlayer toughening on strength and damage tolerance. Composites Science and Technology 168, 467-477. doi:10.1016/j.compscitech.2018.08.037.

[51] Daelemans, L., Kizildag, N., Van Paepegem, W., D'hooge, D.R., De Clerck, K., 2019. Interdiffusing core-shell nanofiber interleaved composites for excellent Mode I and Mode II delamination resistance. Composites Science and Technology 175, 143-150. doi:10.1016/ j.compscitech.2019.03.019.

[52] Dahm, W.J.A., 2010. Technology Horizons a Vision for Air Force Science \& Technology During 2010-2030. USAF HQ, Arlington, VA.

[53] Dai, Y., Feng, M., Zhao, M., 2017. Topology optimization of laminated composite structures with design-dependent loads. Composite Structures 167, 251-261. doi:10.1016/j.compstruct.2017.01.069.

[54] Dao, T.D., Ha, N.S., Goo, N.S., Yu, W.R., 2018. Design, fabrication, and bending test of shape memory polymer composite hinges for space deployable structures. Journal of Intelligent Material Systems and Structures 29, 1560-1574. URL: https://doi.org/10.1177/ 1045389x17742728, doi:10.1177/1045389×17742728.

[55] das Neves Carneiro, G., Antonio, C.C., 2018. A RBRDO approach based on structural robustness and imposed reliability level. Structural and Multidisciplinary Optimization 57, 2411-2429. doi:10.1007/ s00158-017-1870-6.

[56] das Neves Carneiro, G., António, C.C., 2019. Robustness and reliability of composite structures: effects of different sources of uncertainty. International Journal of Mechanics and Materials in Design 15, 93107. doi:10.1007/s10999-017-9401-6.

[57] das Neves Carneiro, G., Conceição António, C., 2019. Reliability-based Robust Design Optimization with the Reliability Index Approach applied to composite laminate structures. Composite Structures 209, 844-855. URL: http: //www.sciencedirect.com/science/article/pii/S0263822318332720, doi:10.1016/j.compstruct.2018.11.012.

[58] Dávila, C.G., Camanho, P.P., Rose, C.A., 2005. Failure criteria for FRP laminates. Journal of Composite Materials 39, 323-345. doi:10.1177/0021998305046452.

[59] Dávila, C.G., Camanho, P.P., Turon, A., 2008. Effective simulation of delamination in aeronautical structures using shells and cohesive elements. Journal of Aircraft 45, 663-672.

[60] Demir, E., Yousefi-Louyeh, P., Yildiz, M., 2019. Design of vari- 
able stiffness composite structures using lamination parameters with fiber steering constraint. Composites Part B: Engineering 165, 733-746. URL: http://www.sciencedirect.com/science/article/pii/ S1359836818336631, doi:10.1016/j.compositesb.2019.02.004.

[61] Deng, J., Yan, J., Cheng, G., 2013. Multi-objective concurrent topology optimization of thermoelastic structures composed of homogeneous porous material. Structural and Multidisciplinary Optimization 47, 583-597. doi:10.1007/s00158-012-0849-6.

[62] Dewalque, F., Collette, J.P., Brüls, O., 2016. Mechanical behaviour of tape springs used in the deployment of reflectors around a solar panel. Acta Astronautica 123, 271-282. doi:10.1016/ j.actaastro.2016.03.029.

[63] Dewalque, F., Rochus, P., Brills, O., 2014. Importance of structural damping in the dynamic analysis of compliant deployable structures. Proceedings of the International Astronautical Congress, IAC 8, 5535-5547.

[64] Dewalque, F., Schwartz, C., Denoël, V., Croisier, J.L., Forthomme, B., Brüls, O., 2018. Experimental and numerical investigation of the nonlinear dynamics of compliant mechanisms for deployable structures. Mechanical Systems and Signal Processing 101, 1-25. doi:10.1016/j.ymssp.2017.08.006.

[65] Dimoka, P., Psarras, S., Kostagiannakopoulou, C., Kostopoulos, V., 2019. Assessing the damage tolerance of Out of Autoclave manufactured carbon fibre reinforced polymers modified with multi-walled carbon nanotubes. Materials 12, 1080. doi:10.3390/ma12071080.

[66] Du, J., Guo, Y., Chen, Z., Sui, Y., 2019. Topology optimization of continuum structures considering damage based on independent continuous mapping method. Acta Mechanica Sinica/Lixue Xuebao 35, 433-444. URL: https: //doi.org/10.1007/s10409-018-0807-7, doi:10.1007/s10409-018-0807-7.

[67] Duan, Z., Yan, J., Lee, I., Wang, J., Yu, T., 2018. Integrated design optimization of composite frames and materials for maximum fundamental frequency with continuous fiber winding angles. Acta Mechanica Sinica/Lixue Xuebao 34, 1084-1094. URL: https:// doi.org/10.1007/s10409-018-0784-x, doi:10.1007/s10409-018-0784-x.

[68] Dubary, N., Taconet, G., Bouvet, C., Vieille, B., 2017. Influence of temperature on the impact behavior and damage tolerance of hybrid woven-ply thermoplastic laminates for aeronautical applications. Composite Structures 168, 663-674. doi:10.1016/ j.compstruct.2017.02.040.

[69] Dutton, S., Kelly, D., Baker, A., 2004. Composite Materials for Aircraft Structures, Second Edition. AIAA. doi:10.2514/4.861680.

[70] Dvorak, G.J., Laws, N., 1987. Analysis of Progressive Matrix Cracking In Composite Laminates II. First Ply Failure. Journal of Composite Materials 21, 309-329. doi:10.1177/002199838702100402.

[71] Elias, A., Laurin, F., Kaminski, M., Gornet, L., 2017. Experimental and numerical investigations of low energy/velocity impact damage generated in 3D woven composite with polymer matrix. Composite Structures 159, 228-239. doi:10.1016/j.compstruct.2016.09.077.

[72] ESA, 2016. Statement of Work AO8702 - Antenna Deployment Arm with Integrated Elastic Hinges. Technical Report. URL: https://artes.esa.int/funding/antenna-deployment-armintegrated-elastic-hinges-artes-ref-5b163-expro.

[73] Esmaeeli, M., Kazemianfar, B., Nami, M.R., 2019. Simultaneous optimization of elastic constants of laminated composites using artificial bee colony algorithm. Advanced Composites and Hybrid Materials 2, 431-443. URL: https://doi.org/10.1007/s42114-019-00106-7, doi:10.1007/s42114-019-00106-7.

[74] Farzan Nasab, F., Geijselaers, H.J., Baran, I., Akkerman, R., de Boer, A., 2018. A level-set-based strategy for thickness optimization of blended composite structures. Composite Structures 206, 903-920. URL: http://www.sciencedirect.com/science/article/pii/ s0263822318307104, doi:10.1016/j.compstruct.2018.08.059.

[75] Fenci, G.E., Currie, N.G.R., 2017. Deployable structures classification: A review. International Journal of Space Structures 32, $112-130$.

[76] Feraboli, P., Kedward, K.T., 2006. A new composite structure impact performance assessment program. Composites Science and
Technology 66, 1336-1347. doi:10.1016/j.compscitech.2005.09.009.

[77] Fernandes, P., Marques, R., Pinto, R., Mimoso, P., Rodrigues, J., Silva, A., Rodrigues, G., Correia, N., 2020. Design and optimization of a self-deployable composite structure (Diseño y optimización de una estructura compuesta auto desplegable). Materiales Compuestos 4, 80-89. URL: https://revista.aemac.org/materiales-compuestos/ article/view/403.

[78] Fernandez, F., Compel, W.S., Lewicki, J.P., Tortorelli, D.A., 2019. Optimal design of fiber reinforced composite structures and their direct ink write fabrication. Computer Methods in Applied Mechanics and Engineering 353, 277-307. URL: http: //www.sciencedirect.com/science/article/pii/S0045782519302798, doi:10.1016/j.cma.2019.05.010.

[79] Ferraro, S., Pellegrino, S., 2018. Self-deployable joints for ultra-light space structures, in: AIAA Spacecraft Structures Conference, 2018, AIAA Spacecraft Structures Conference, Kissimmee, Florida. pp. 0694-0707. doi:10.2514/6.2018-0694.

[80] Ferraro, S., Pellegrino, S., 2019. Topology optimization of composite self-deployable thin shells with cutouts, in: AIAA Scitech 2019 Forum, p. 1524. doi:10.2514/6.2019-1524.

[81] Firsov, L.L., Fedorenko, A.N., Fedulov, B.N., 2020. Residual strength estimation based on topology optimization algorythm. ECCM 2018 18th European Conference on Composite Materials , 1-19.

[82] Francesconi, L., Aymerich, F., 2017. Numerical simulation of the effect of stitching on the delamination resistance of laminated composites subjected to low-velocity impact. Composite Structures 159, 110-120. doi:10.1016/j.compstruct.2016.09.050.

[83] Fu, J., Xia, L., Gao, L., Xiao, M., Li, H., 2019. Topology Optimization of Periodic Structures with Substructuring. Journal of Mechanical Design, Transactions of the ASME 141. URL: https: //doi.org/10.1115/1.4042616, doi:10.1115/1.4042616.

[84] Fuchs, M.B., Paley, M., Miroshny, E., 1999. Aboudi micromechanical model for topology design of structures. Computers and Structures 73, 355-362. doi:10.1016/S0045-7949(98/00260-0.

[85] Gao, J., Luo, Z., Xia, L., Gao, L., 2019. Concurrent topology optimization of multiscale composite structures in Matlab. Structural and Multidisciplinary Optimization 60, 2621-2651. URL: https:// doi.org/10.1007/s00158-019-02323-6, doi:10.1007/s00158-019-023236.

[86] Gao, S.L., Kim, J.K., 2001. Cooling rate influences in carbon fibre/PEEK composites. Part IIII Impact damage performance. Composites - Part A: Applied Science and Manufacturing 32, 775-785. doi:10.1016/S1359-835X(00/00189-5.

[87] Gao, T., Zhang, W., Duysinx, P., 2012. A bi-value coding parameterization scheme for the discrete optimal orientation design of the composite laminate. International Journal for Numerical Methods in Engineering 91, 98-114. doi:10.1002/nme.4270.

[88] Gao, T., Zhang, W.H., Duysinx, P., 2013. Simultaneous design of structural layout and discrete fiber orientation using bi-value coding parameterization and volume constraint. Structural and Multidisciplinary Optimization 48, 1075-1088. doi:10.1007/s00158-013-0948-z.

[89] Givois, D., Sicre, J., Mazoyer, T., 2001. A low cost hinge for appendices deployment: Design, test and applications, in: European Space Agency, (Special Publication) ESA SP, pp. 145-151.

[90] Gliszczynski, A., Kubiak, T., Rozylo, P., Jakubczak, P., Bieniaś, J., 2019. The response of laminated composite plates and profiles under low-velocity impact load. Composite Structures 207, 1-12. doi:10.1016/j.compstruct.2018.09.005.

[91] González, E.V., Maimí, P., Camanho, P.P., Turon, A., Mayugo, J.A., 2012. Simulation of drop-weight impact and compression after impact tests on composite laminates. Composite Structures 94, 3364-3378. doi:10.1016/j.compstruct.2012.05.015.

[92] Gouzman, I., Grossman, E., Verker, R., Atar, N., Bolker, A., Eliaz, N., 2019. Advances in Polyimide-Based Materials for Space Applications. Advanced Materials 31, 1807738.

[93] Greve, L., Pickett, A.K., 2006. Delamination testing and modelling for composite crash simulation. Composites Science and Technology 66, 816-826. doi:10.1016/j.compscitech.2004.12.042. 
[94] Guest, S.D., Pellegrino, S., 1996. A new concept for solid surface deployable antennas. Acta Astronautica 38, 103-113. doi:10.1016/ 0094-5765(96/00009-4.

[95] Hadaegh, F.Y., Chung, S., Manohara, H.M., 2016. On Development of 100-Gram-Class Spacecraft for Swarm Applications. IEEE Systems Journal 10, 673-684. doi:10.1109/JSYST.2014.2327972.

[96] Hamel, C.M., Roach, D.J., Long, K.N., Demoly, F., Dunn, M.L., Qi, H.J., 2019. Machine-learning based design of active composite structures for 4D printing. Smart Materials and Structures 28, 65005. URL: http://dx.doi.org/10.1088/1361-665X/ab1439, doi:10.1088/1361665X/ab1439.

[97] Hancox, N., 1996. Engineering mechanics of composite materials. volume 17. Oxford university press New York. doi:10.1016/s02613069(97/87195-6.

[98] Hansel, W., Becker, W., 1999. Layerwise adaptive topology optimization of laminate structures. Engineering Computations (Swansea, Wales) 16, 841-851. doi:10.1108/02644409910298156.

[99] Hansel, W., Treptow, A., Becker, W., Freisleben, B., 2002. A heuristic and a genetic topology optimization algorithm for weight-minimal laminate structures. Composite Structures 58, 287-294. doi:10.1016/ S0263-8223(02/00048-X.

[100] Hart, K.R., Chia, P.X., Sheridan, L.E., Wetzel, E.D., Sottos, N.R., White, S.R., 2017a. Comparison of Compression-After-Impact and Flexure-After-Impact protocols for 2D and 3D woven fiber-reinforced composites. Composites Part A: Applied Science and Manufacturing 101, 471-479. doi:10.1016/j.compositesa.2017.07.005.

[101] Hart, K.R., Chia, P.X., Sheridan, L.E., Wetzel, E.D., Sottos, N.R., White, S.R., 2017b. Mechanisms and characterization of impact damage in 2D and 3D woven fiber-reinforced composites. Composites Part A: Applied Science and Manufacturing 101, 432-443. doi:10.1016/j.compositesa.2017.07.004.

[102] Hoffait, S., Brüls, O., Granville, D., Cugnon, F., Kerschen, G., 2010. Dynamic analysis of the self-locking phenomenon in tapespring hinges. Acta Astronautica 66, 1125-1132. doi:10.1016/ j.actaastro.2009.10.001.

[103] Hongkarnjanakul, N., Bouvet, C., Rivallant, S., 2013. Validation of low velocity impact modelling on different stacking sequences of CFRP laminates and influence of fibre failure. Composite Structures 106, 549-559. doi:10.1016/j.compstruct.2013.07.008.

[104] Hooke, R., Jeeves, T.A., 1961. "Direct Search" Solution of Numerical and Statistical Problems. Journal of the ACM (JACM) 8, 212-229. doi:10.1145/321062.321069.

[105] Howell, L.L., Magleby, S.P., Olsen, B.M., 2013. Handbook of Compliant Mechanisms. John Wiley \& Sons Ltd. doi:10.1002/ 9781118516485, arXiv: 9809069v1.

[106] Huang, X., Xie, Y.M., 2010. Evolutionary Topology Optimization of Continuum Structures: Methods and Applications. John Wiley \& Sons. doi:10.1002/9780470689486.

[107] Icten, B.M., 2015. Low temperature effect on single and repeated impact behavior of woven glass-epoxy composite plates. Journal of Composite Materials 49, 1171-1178. doi:10.1177/0021998314531309.

[108] Icten, B.M., Kiral, B.G., Deniz, M.E., 2013. Impactor diameter effect on low velocity impact response of woven glass epoxy composite plates. Composites Part B: Engineering 50, 325-332. doi:10.1016/ j.compositesb.2013.02.024

[109] Jansen, M., Pierard, O., 2020. A hybrid density/level set formulation for topology optimization of functionally graded lattice structures. Computers and Structures 231, 106205. URL: http: //www.sciencedirect.com/science/article/pii/s0045794920300080, doi:10.1016/j.compstruc.2020.106205.

[110] Jeong, J.W., Yoo, Y.I., Shin, D.K., Lim, J.H., Kim, K.W., Lee, J.J., 2014. A novel tape spring hinge mechanism for quasi-static deployment of a satellite deployable using shape memory alloy. Review of Scientific Instruments 85, 25001. doi:10.1063/1.4862470.

[111] Jiang, D., Hoglund, R., Smith, D.E., 2019. Continuous fiber angle topology optimization for polymer composite deposition additive manufacturing applications. Fibers 7, 14. doi:10.3390/FIB7020014.

[112] Jin, P., Wang, Y., Zhong, X., Yang, J., Sun, Z., 2018. Blending design of composite laminated structure with panel permutation sequence. Aeronautical Journal 122, 333-347. URL: https://www.cambridge.org/core/article/blending-design-of-

composite-laminated-structure-with-panel-permutation-sequence/ F65A886317BE4723617EEEE964987E83, doi:10.1017/aer.2017.132.

[113] Johnston, J.P., Roberts, G.D., Miller, S.G., 2019. A Design Methodology for Optimizing and Integrating Composite Materials in Gear Structures. NASA Technical Reports Server, 20.

[114] Jones, D.R., Schonlau, M., Welch, W.J., 1998. Efficient Global Optimization of Expensive Black-Box Functions. Journal of Global Optimization 13, 455-492. doi:10.1023/A: 1008306431147.

[115] Jung, K.H., Kim, D.H., Kim, H.J., Park, S.H., Jhang, K.Y., Kim, H.S., 2017. Finite element analysis of a low-velocity impact test for glass fiber-reinforced polypropylene composites considering mixed-mode interlaminar fracture toughness. Composite Structures 160, 446-456. doi:10.1016/j.compstruct.2016.10.093.

[116] Karakuzu, R., Erbil, E., Aktas, M., 2010. Impact characterization of glass/epoxy composite plates: An experimental and numerical study. Composites Part B: Engineering 41, 388-395. doi:10.1016/ j.compositesb.2010.02.003.

[117] Karthikeyan, K., Russell, B.P., Deshpande, V.S., Fleck, N.A., 2012. Multi-hit armour characterisation of metal-composite bi-layers. Journal of Mechanics of Materials and Structures 7, 721-734. doi:10.2140/ jomms.2012.7.721.

[118] Khodaygan, S., Bohlooly, M., 2020. Multi-objective optimal design of stiffened laminated composite cylindrical shell with piezoelectric actuators. International Journal on Interactive Design and Manufacturing 14, 595-611. URL: https://doi.org/10.1007/s12008-020-00644-1, doi:10.1007/s12008-020-00644-1.

[119] Kiper, G., Söylemez, E., 2009. Deployable space structures, in: RAST 2009 - Proceedings of 4th International Conference on Recent Advances Space Technologies, Istanbul, turkey. pp. 131-138. doi:10.1109/RAST.2009.5158183.

[120] Klarbring, A., Torstenfelt, B., 2010. Dynamical systems and topology optimization. Structural and Multidisciplinary Optimization 42, 179192. doi:10.1007/s00158-010-0479-9.

[121] Koiter, W.T., 1945. On the stability of elastic equilibrium; Translation of'Over de Stabiliteit von het elastisch evenwich', in: NASA TT F10,833. Polytechnic Institute Delft, HJ Paris Publisher Amsterdam.

[122] Kristinsdottir, B.P., Zabinsky, Z.B., 1994. Including manufacturing tolerances in composite design, in: Collection of Technical Papers - AIAA/ASME/ASCE/AHS/ASC Structures, Structural Dynamics and Materials Conference, pp. 1413-1422. doi:10.2514/6.1994-1495.

[123] Kroon, M., Borst, G., Grimminck, M., Robroek, M., Geuskens, F., Defence, A., 2015. Articulated Deployment System for Antenna Reflectors, in: Proc. 16th European Space Mechanisms and Tribology Symposium, Bilbao, pp. 23-25.

[124] Kwok, K., Pellegrino, S., 2010. Shape recovery of viscoelastic deployable structures, in: Collection of Technical Papers AIAA/ASME/ASCE/AHS/ASC Structures, Structural Dynamics and Materials Conference, p. 2606. doi:10.2514/6.2010-2606.

[125] Kwok, K., Pellegrino, S., 2011. Viscoelastic effects in tape-springs, in: Collection of Technical Papers - AIAA/ASME/ASCE/AHS/ASC Structures, Structural Dynamics and Materials Conference, p. 2022. doi:10.2514/6.2011-2022.

[126] Kwok, K., Pellegrino, S., 2012. Micromechanical modeling of deployment and shape recovery of thin-walled viscoelastic composite space structures, in: Collection of Technical Papers AIAA/ASME/ASCE/AHS/ASC Structures, Structural Dynamics and Materials Conference, p. 1910. doi:10.2514/6.2012-1910.

[127] Kwok, K., Pellegrino, S., 2013. Folding, stowage, and deployment of viscoelastic tape springs. AIAA Journal 51, 1908-1918. doi:10.2514/ 1.J052269.

[128] Le, V.L., Le, V.T., Goo, N.S., 2019. Deployment performance of shape memory polymer composite hinges at low temperature. Journal of Intelligent Material Systems and Structures 30, 26252638. URL: https://doi.org/10.1177/1045389×19873403, doi:10.1177/ $1045389 \times 19873403$ 
[129] Lee, J., Kim, D., Nomura, T., Dede, E.M., Yoo, J., 2018. Topology optimization for continuous and discrete orientation design of functionally graded fiber-reinforced composite structures. Composite Structures 201, 217-233. URL: http: //www.sciencedirect.com/science/article/pii/S0263822318305798, doi:10.1016/j.compstruct.2018.06.020.

[130] Lee, J.W., Kim, J.J., Yoon, G.H., 2019. Stress constraint topology optimization using layerwise theory for composite laminates. Composite Structures 226, 111184. URL: http: //www.sciencedirect.com/science/article/pii/S0263822318335724, doi:10.1016/j.compstruct.2019.111184.

[131] Lengyel, A., You, Z., 2004. Bifurcations of SDOF mechanisms using catastrophe theory. International Journal of Solids and Structures 41, 559-568.

[132] Li, F., Liu, Y., Leng, J., 2019a. Progress of shape memory polymers and their composites in aerospace applications. Smart Materials and Structures 28, 103003. URL: http://dx.doi.org/10.1088/1361-665X/ ab3d5f, doi:10.1088/1361-665X/ab3d5f.

[133] Li, F., Scarpa, F., Lan, X., Liu, L., Liu, Y., Leng, J., $2019 b$. Bending shape recovery of unidirectional carbon fiber reinforced epoxy-based shape memory polymer composites. Composites Part A: Applied Science and Manufacturing 116, 169179. URL: http://www.sciencedirect.com/science/article/pii/ S1359835X18304330, doi:10.1016/j.compositesa.2018.10.037.

[134] Li, H., Luo, Z., Xiao, M., Gao, L., Gao, J., 2019c. A new multiscale topology optimization method for multiphase composite structures of frequency response with level sets. Computer Methods in Applied Mechanics and Engineering 356, 116144. URL: http://www.sciencedirect.com/science/article/pii/ S0045782519304165, doi:10.1016/j.cma.2019.07.020.

[135] Li, S., Fang, H., Sadeghi, S., Bhovad, P., Wang, K., 2019d. Architected origami materials: How folding creates sophisticated mechanical properties. Advanced materials 31, 1805282.

[136] Liu, H., Falzon, B.G., Tan, W., 2018a. Experimental and numerical studies on the impact response of damage-tolerant hybrid unidirectional/woven carbon-fibre reinforced composite laminates. Composites Part B: Engineering 136, 101-118. doi:10.1016/ j.compositesb.2017.10.016.

[137] Liu, H., Falzon, B.G., Tan, W., 2018b. Predicting the CompressionAfter-Impact (CAI) strength of damage-tolerant hybrid unidirectional/woven carbon-fibre reinforced composite laminates. Composites Part A: Applied Science and Manufacturing 105, 189-202. doi:10.1016/j.compositesa.2017.11.021.

[138] Liu, L., Yan, J., Cheng, G., 2008. Optimum structure with homogeneous optimum truss-like material. Computers and Structures 86, 1417-1425. doi:10.1016/j.compstruc.2007.04.030.

[139] Liu, T., Liu, L., Yu, M., Li, Q., Zeng, C., Lan, X., Liu, Y., Leng, J., 2018c. Integrative hinge based on shape memory polymer composites: Material, design, properties and application. Composite Structures 206, 164-176. URL: http: //www.sciencedirect.com/science/article/ pii/s0263822318312170, doi:10.1016/j.compstruct.2018.08.041.

[140] Liu, X., Featherston, C.A., Kennedy, D., 2019. Two-level layup optimization of composite laminate using lamination parameters. Composite Structures 211, 337-350. URL: http: //www.sciencedirect.com/science/article/pii/S0263822318325753, doi:10.1016/j.compstruct.2018.12.054.

[141] Liu, Z., Lan, X., Bian, W., Liu, L., Li, Q., Liu, Y., Leng, J., 2020. Design, material properties and performances of a smart hinge based on shape memory polymer composites. Composites Part B: Engineering 193, 108056. URL: http://www.sciencedirect.com/science/article/ pii/S1359836819328677, doi:10.1016/j.compositesb.2020.108056.

[142] Luan, K., Gu, B., 2015. Energy absorption of three-dimensional angle-interlock woven composite under ballistic penetration based on a multi-scale finite element model. International Journal of Damage Mechanics 24, 3-20. doi:10.1177/1056789514520800.

[143] Ma, H.L., Jia, Z., Lau, K.T., Leng, J., Hui, D., 2016. Impact properties of glass fiber/epoxy composites at cryogenic environment. Composites Part B: Engineering 92, 210-217. doi:10.1016/ j.compositesb.2016.02.013.

[144] Ma, Z.D., Kikuchi, N., Pierre, C., Raju, B., 2006. Multidomain topology optimization for structural and material designs. Journal of Applied Mechanics, Transactions ASME 73, 565-573. doi:10.1115/ 1.2164511.

[145] Mahzan, S., Fitri, M., Zaleha, M., 2017. UV radiation effect towards mechanical properties of Natural Fibre Reinforced Composite material: A Review, in: IOP Conference Series: Materials Science and Engineering, IOP Publishing. p. 12021.

[146] Maji, A.K., Mahnke, S.A., 2004. A Review of the Degradation of Composites in Mid Earth Orbit. Engineering, Construction, and Operations in Challenging Environments: Earth and Space 2004, 567-572.

[147] Mallikarachchi, H., Pellegrino, S., 2008. Simulation of Quasi-Static Folding and Deployment of Ultra-Thin Composite Structures, in: 49th AIAA / ASME / ASCE / AHS / ASC Structures, Structural Dynamics, and Materials Conference, 16th AIAA / ASME / AHS Adaptive Structures Conference, 10th AIAA Non-Deterministic Approaches Conference, 9th AIAA Gossamer Spacecraft Forum, 4th AIAA Multidisc, p. 2053. doi:10.2514/6.2008-2053.

[148] Mallikarachchi, H.M., Pellegrino, S., 2009. Deployment dynamics of composite booms with integral slotted hinges, in: Collection of Technical Papers - AIAA/ASME/ASCE/AHS/ASC Structures, Structural Dynamics and Materials Conference, p. 2631. doi:10.2514/6.2009-2631.

[149] Mallikarachchi, H.M., Pellegrino, S., 2010. Optimized designs of composite booms with integral tape-spring hinges, in: Collection of Technical Papers - AIAA/ASME/ASCE/AHS/ASC Structures, Structural Dynamics and Materials Conference. doi:10.2514/6.20102750.

[150] Mallikarachchi, H.M., Pellegrino, S., 2011a. Design and validation of thin-walled composite deployable booms with tape-spring hinges, in: Collection of Technical Papers - AIAA/ASME/ASCE/AHS/ASC Structures, Structural Dynamics and Materials Conference. doi:10.2514/6.2011-2019.

[151] Mallikarachchi, H.M., Pellegrino, S., 2011b. Quasi-static folding and deployment of ultrathin composite tape-spring hinges. Journal of Spacecraft and Rockets 48, 187-198. URL: http: //arc.aiaa.org/ doi/10.2514/1.47321, doi:10.2514/1.47321.

[152] Mallikarachchi, H.M., Pellegrino, S., 2013. Failure criterion for twoply plain-weave CFRP laminates. Journal of Composite Materials 47, 1357-1375. doi:10.1177/0021998312447208.

[153] Mallikarachchi, H.M., Pellegrino, S., 2014a. Deployment dynamics of ultrathin composite booms with tape-spring hinges. Journal of Spacecraft and Rockets 51, 604-613. doi:10.2514/1.A32401.

[154] Mallikarachchi, H.M., Pellegrino, S., 2014b. Design of Ultrathin composite self-deployable booms. Journal of Spacecraft and Rockets 51, 1811-1821. doi:10.2514/1.A32815.

[155] Mallikarachchi, H.Y.C., 2011. Thin-walled composite deployable booms with tape-spring hinges. URL: http://www.dspace.cam.ac.uk/ handle/1810/239395.

[156] Mansfield, E.H., 1973. Large-deflexion torsion and flexure of initially curved strips. Proceedings of the Royal Society of London. A. Mathematical and Physical Sciences 334, 279-298. doi:10.1098/ rspa.1973.0092.

[157] Manual, A.U., Volume, I.I., 2003. Version 6.4. Abaqus Inc 1080.

[158] Mao, H., Ganga, P.L., Ghiozzi, M., Ivchenko, N., Tibert, G., 2017. Deployment of Bistable Self-Deployable Tape Spring Booms Using a Gravity Offloading System. Journal of Aerospace Engineering 30, 4017007. doi:10.1061/ (ASCE/AS.1943-5525.0000709.

[159] Marks, G.W., Reilly, M.T., Huff, R.L., 2002. The lightweight deployable antenna for the MARSIS experiment on the Mars express spacecraft, in: 36th Aerospace Mechanisms Symp, pp. 183-196.

[160] Matadi Boumbimba, R., Coulibaly, M., Khabouchi, A., KinviDossou, G., Bonfoh, N., Gerard, P., 2017. Glass fibres reinforced acrylic thermoplastic resin-based tri-block copolymers composites: Low velocity impact response at various temperatures. Composite Structures 160, 939-951. doi:10.1016/j.compstruct.2016.10.127. 
[161] Matlab, V., 2010. 7.10. 0 (R2010a). The MathWorks Inc., Natick, Massachusetts .

[162] McGugan, M., Pereira, G., Sorensen, B.F., Toftegaard, H., Branner, K., 2015. Damage tolerance and structural monitoring for wind turbine blades. Philosophical Transactions of the Royal Society A: Mathematical, Physical and Engineering Sciences 373, 20140077. doi:10.1098/rsta.2014.0077.

[163] Meng, L., Zhang, W., Quan, D., Shi, G., Tang, L., Hou, Y., Breitkopf, P., Zhu, J., Gao, T., 2020. From Topology Optimization Design to Additive Manufacturing: Today's Success and Tomorrow's Roadmap. Archives of Computational Methods in Engineering 27, 805-830. doi:10.1007/s11831-019-09331-1.

[164] Misra, A., Demkowicz, M.J., Zhang, X., Hoagland, R.G., 2007. The radiation damage tolerance of ultra-high strength nanolayered composites. Jom 59, 62-65.

[165] Mitrevski, T., Marshall, I.H., Thomson, R., 2006. The influence of impactor shape on the damage to composite laminates. Composite Structures 76, 116-122. doi:10.1016/j.compstruct.2006.06.017.

[166] Mittelstedt, C., 2020. Buckling and Post-Buckling of Thin-Walled Composite Laminated Beams-A Review of Engineering Analysis Methods. Applied Mechanics Reviews 72. URL: https://doi.org/ 10.1115/1.4045680, doi:10.1115/1.4045680.

[167] Mobrem, M., Adams, D.S., 2009. Deployment analysis of lenticular jointed antennas onboard the mars express spacecraft. Journal of Spacecraft and Rockets 46, 394-402. doi:10.2514/1.36890.

[168] Mobrem, M., Peterson, L.D., Cormarkovic, V., Montazersadgh, F., 2017. An evaluation of structural analysis methodologies for space deployable structures, in: 4th AIAA Spacecraft Structures Conference, 2017, p. 851. doi:10.2514/6.2017-0851.

[169] Murphey, T.W., Francis, W.H., Davis, B.L., Mejia-Ariza, J., Santer, M., Footdale, J.N., Schmid, K., Soykasap, O., Guidanean, K., Warren, P.A., 2015. High strain composites, in: 2nd AIAA Spacecraft Structures Conference. doi:10.2514/6.2015-0942.

[170] Murphey, T.W., Pellegrino, S., 2004. A novel actuated composite tapespring for deployable structures, in: Collection of Technical Papers - AIAA/ASME/ASCE/AHS/ASC Structures, Structural Dynamics and Materials Conference, pp. 260-270.

[171] Nasab, F.F., Geijselaers, H.J., Baran, I., Akkerman, R., de Boer, A., 2020. Optimization of the interacting stiffened skins and ribs made of composite materials. AIAA Journal 58, 1836-1850. URL: https://doi.org/10.2514/1.J058415, doi:10.2514/1.J058415.

[172] Nash, N.H., Young, T.M., McGrail, P.T., Stanley, W.F., 2015. Inclusion of a thermoplastic phase to improve impact and post-impact performances of carbon fibre reinforced thermosetting composites - A review. Materials and Design 85, 582-597. doi:10.1016/ j.matdes.2015.07.001.

[173] Nguyen, D.H., Wang, H., Ye, F., Hu, W., 2020. Investigation and multi-scale optimization design of woven composite cut-out structures. URL: https://doi.org/10.1108/EC-08-2019-0361, doi:10.1108/ EC- $08-2019-0361$.

[174] Nikbakht, S., Kamarian, S., Shakeri, M., 2019. A review on optimization of composite structures Part II: Functionally graded materials. Composite Structures 214, 83-102. doi:10.1016/ j.compstruct.2019.01.105.

[175] Nikbakt, S., Kamarian, S., Shakeri, M., 2018. A review on optimization of composite structures Part I: Laminated composites. Composite Structures 195, 158-185. URL: http: //www.sciencedirect.com/science/article/pii/S0263822317336279, doi:10.1016/j.compstruct.2018.03.063.

[176] Nishi, S., Terada, K., Kato, J., Nishiwaki, S., Izui, K., 2018. Twoscale topology optimization for composite plates with in-plane periodicity. International Journal for Numerical Methods in Engineering 113, 1164-1188. doi:10.1002/nme.5545.

[177] Niu, B., Olhoff, N., Lund, E., Cheng, G., 2010. Discrete material optimization of vibrating laminated composite plates for minimum sound radiation. International Journal of Solids and Structures 47, 2097-2114. doi:10.1016/j.ijsolstr.2010.04.008.

[178] Nomura, T., Dede, E.M., Lee, J., Yamasaki, S., Matsumori, T.,
Kawamoto, A., Kikuchi, N., 2015. General topology optimization method with continuous and discrete orientation design using isoparametric projection. International Journal for Numerical Methods in Engineering 101, 571-605. URL: https://doi.org/10.1002/nme.4799, doi:10.1002/nme.4799.

[179] Nomura, T., Kawamoto, A., Kondoh, T., Dede, E.M., Lee, J., Song, Y., Kikuchi, N., 2019. Inverse design of structure and fiber orientation by means of topology optimization with tensor field variables. Composites Part B: Engineering 176, 107187. URL: http://www.sciencedirect.com/science/article/pii/ S1359836819307218, doi:10.1016/j.compositesb.2019.107187.

[180] Panesar, A., Abdi, M., Hickman, D., Ashcroft, I., 2018. Strategies for functionally graded lattice structures derived using topology optimisation for additive manufacturing. Additive Manufacturing 19, 81-94.

[181] Peterson, M.E., Murphey, T.W., 2013. Large deformation bending of thin composite tape spring laminates, in: Collection of Technical Papers - AIAA/ASME/ASCE/AHS/ASC Structures, Structural Dynamics and Materials Conference, p. 1667.

[182] Pietrak, K., Wiśniewski, T.S., 2014. A review of models for effective thermal conductivity of composite materials. Journal of Power Technologies; Vol 95 No 1 (2015) URL: https://papers.itc.pw.edu.pl/ index.php/JPT/article/view/463.

[183] Pinho, S.T., Dávila, C.G., Camanho, P.P., Iannucci, L., Robinson, P., 2005. Failure Models and Criteria for FRP Under In-Plane or ThreeDimensional Stress States Including Shear Non-linearity. Nasa/Tm2005-213530, 68doi:NASA/TM-2005-213530.

[184] Piovesan, D., Zaccariotto, M., Bettanini, C., Pertile, M., Debei, S., 2016. Design and validation of a carbon-fiber collapsible hinge for space applications: A deployable boom. Journal of Mechanisms and Robotics 8, 031007-031018. doi:10.1115/1.4032271.

[185] Potluri, P., Hogg, P., Arshad, M., Jetavat, D., Jamshidi, P., 2012. Influence of fibre architecture on impact damage tolerance in 3D woven composites. Applied Composite Materials 19, 799-812. doi:10.1007/s10443-012-9256-9.

[186] Puck, A., Schürmann, H., 2004. Failure analysis of FRP laminates by means of physically based phenomenological models, in: Failure Criteria in Fibre-Reinforced-Polymer Composites. Elsevier, pp. 832876. doi:10.1016/B978-008044475-8/50028-7.

[187] Puig, L., Barton, A., Rando, N., 2010. A review on large deployable structures for astrophysics missions. Acta Astronautica 67, 12-26. doi:10.1016/j.actaastro.2010.02.021.

[188] Reddy, M.P., Mukherjee, S., Ganguli, R., 2020. Optimal design of damage tolerant composite using ply angle dispersion and enhanced bat algorithm. Neural Computing and Applications 32, 3387-3406. URL: https://doi.org/10.1007/s00521-019-04455-8, doi: $10.1007 / \mathrm{s} 00521-019-04455-8$.

[189] Ren, Y., Jinwu, X., Zheqi, L., Tiantian, Z., 2016. A novel topology optimization method for composite beams. Proceedings of the Institution of Mechanical Engineers, Part G: Journal of Aerospace Engineering 230, 1153-1163. doi:10.1177/0954410015605547.

[190] Reyes, G., Sharma, U., 2010. Modeling and damage repair of woven thermoplastic composites subjected to low velocity impact. Composite Structures 92, 523-531. doi:10.1016/j.compstruct.2009.08.038.

[191] Rheinboldt, W.C., Morgan, A., 1988. Solving Polynomial Systems Using Continuation for Engineering and Scientific Problems.. volume 51. Siam. doi:10.2307/2008602.

[192] Richardson, M.O., Wisheart, M.J., 1996. Review of low-velocity impact properties of composite materials. Composites Part A: Applied Science and Manufacturing 27, 1123-1131. doi:10.1016/1359835x (96/00074-7.

[193] Rivallant, S., Bouvet, C., Hongkarnjanakul, N., 2013. Failure analysis of CFRP laminates subjected to compression after impact: FE simulation using discrete interface elements. Composites Part A: Applied Science and Manufacturing 55, 83-93. doi:10.1016/ j.compositesa.2013.08.003.

[194] Romano, F., Sorrentino, A., Pellone, L., Mercurio, U., Notarnicola, L., 2019. New design paradigms and approaches for aircraft composite 
structures. Multiscale and Multidisciplinary Modeling, Experiments and Design 2, 75-87. doi:10.1007/s41939-018-0034-8.

[195] Rongrong, X., Zhengyin, Y., Kun, Y., Gang, W., 2019. Composite material structure optimization design and aeroelastic analysis on forward swept wing. Proceedings of the Institution of Mechanical Engineers, Part G: Journal of Aerospace Engineering 233, 46794695. URL: https://doi.org/10.1177/0954410018807810, doi:10.1177/ 0954410018807810.

[196] Rossum, G.V., 2003. The Python Language Reference Manual, Release 3.5.1. Network Theory Ltd.

[197] Rozvany, G.I., 2009. A critical review of established methods of structural topology optimization. Structural and Multidisciplinary Optimization 37, 217-237. doi:10.1007/s00158-007-0217-0.

[198] Rozylo, P., Debski, H., Kubiak, T., 2017. A model of low-velocity impact damage of composite plates subjected to CompressionAfter-Impact (CAI) testing. Composite Structures 181, 158-170. doi:10.1016/j.compstruct.2017.08.097.

[199] Russo, P., Langella, A., Papa, I., Simeoli, G., Lopresto, V., 2016a. Low-velocity Impact and Flexural Properties of Thermoplastic Polyurethane/Woven Glass Fabric Composite Laminates. Procedia Engineering 167, 190-196. doi:10.1016/j.proeng.2016.11.687.

[200] Russo, P., Langella, A., Papa, I., Simeoli, G., Lopresto, V., 2017. Thermoplastic polyurethane/glass fabric composite laminates: Low velocity impact behavior under extreme temperature conditions. Composite Structures 166, 146-152. doi:10.1016/j.compstruct.2017.01.054.

[201] Russo, P., Simeoli, G., Sorrentino, L., Iannace, S., 2016b. Effect of the compatibilizer content on the quasi-static and low velocity impact responses of glass woven fabric/polypropylene composites. Polymer Composites 37, 2452-2459. doi:10.1002/pc.23430.

[202] Safonov, A.A., 2019. 3D topology optimization of continuous fiber-reinforced structures via natural evolution method. Composite Structures 215, 289-297. URL: http: //www.sciencedirect.com/science/article/pii/S0263822318305609, doi:10.1016/j.compstruct.2019.02.063.

[203] Sakovsky, M., 2018. Design and characterisation of dual-matrix composite deployable space structures.

[204] Sakovsky, M., Maqueda, I., Karl, C., Pellegrino, S., Costantine, J., 2015. Dual-matrix composite wideband antenna structures for CubeSats, in: 2nd AIAA Spacecraft Structures Conference. American Institute of Aeronautics and Astronautics. AIAA SciTech Forum. URL: https://doi.org/10.2514/6.2015-0944, doi:10.2514/6.2015-0944.

[205] Sakovsky, M., Pellegrino, S., 2019. Closed cross-section dual-matrix composite hinge for deployable structures. Composite Structures 208, 784-795. URL: http://www.sciencedirect.com/science/article/pii/ S0263822318324681, doi:10.1016/j.compstruct.2018.10.040.

[206] Sakovsky, M., Pellegrino, S., Mallikarachchi, H.M., 2016. Folding and deployment of closed cross-section dual-matrix composite booms, in: 3rd AIAA Spacecraft Structures Conference. doi:10.2514/6.20160970.

[207] Samborski, S., 2017. Analysis of the end-notched flexure test configuration applicability for mechanically coupled fiber reinforced composite laminates. Composite Structures 163, 342-349. doi:10.1016/ j.compstruct.2016.12.051.

[208] San, B., Xiao, Z., Qiu, Y., 2019. Simultaneous Shape and Stacking Sequence Optimization of Laminated Composite Free-Form Shells Using Multi-Island Genetic Algorithm. Advances in Civil Engineering 2019, 2056460. URL: https://doi.org/10.1155/2019/2056460, doi:10.1155/2019/2056460.

[209] Santiago, R., Cantwell, W., Alves, M., 2017. Impact on thermoplastic fibre-metal laminates: Experimental observations. Composite Structures 159, 800-817. doi:10.1016/j.compstruct.2016.10.011.

[210] Santos, R.A., Reis, P.N., Santos, M.J., Coelho, C.A., 2017a. Effect of distance between impact point and hole position on the impact fatigue strength of composite laminates. Composite Structures 168, 33-39. doi:10.1016/j.compstruct.2017.02.045.

[211] Santos, R.A., Reis, P.N., Silva, F.G., de Moura, M.F., 2017b. Influence of inclined holes on the impact strength of CFRP composites. Composite Structures 172, 130-136. doi:10.1016/ j.compstruct.2017.03.086.

[212] Sarasini, F., Tirillò, J., D’Altilia, S., Valente, T., Santulli, C., Touchard, F., Chocinski-Arnault, L., Mellier, D., Lampani, L., Gaudenzi, P., 2016. Damage tolerance of carbon/flax hybrid composites subjected to low velocity impact. Composites Part B: Engineering 91, 144-153. doi:10.1016/j.compositesb.2016.01.050.

[213] Seffen, K.A., Pellegrino, S., 1999. Deployment dynamics of tape springs. Proceedings of the Royal Society A: Mathematical, Physical and Engineering Sciences 455, 1003-1048. doi:10.1098/ rspa.1999.0347.

[214] Sellitto, A., 2020. Optimum design of damage resistant reinforced composite panels, in: Key Engineering Materials, Trans Tech Publ. pp. 37-42. doi:10.4028/www.scientific.net/KEM.827.37.

[215] Seltzer, R., González, C., Muñoz, R., Llorca, J., Blanco-Varela, T., 2013. X-ray microtomography analysis of the damage micromechanisms in 3D woven composites under low-velocity impact. Composites Part A: Applied Science and Manufacturing 45, 49-60. doi:10.1016/j.compositesa.2012.09.017.

[216] Setoodeh, S., Abdalla, M.M., Gürdal, Z., 2005. Combined topology and fiber path design of composite layers using cellular automata. Structural and Multidisciplinary Optimization 30, 413-421. doi:10.1007/s00158-005-0528-y.

[217] Sevkat, E., Liaw, B., Delale, F., 2013. Drop-weight impact response of hybrid composites impacted by impactor of various geometries. Materials and Design 52,67-77. doi:10.1016/j.matdes.2013.05.016.

[218] Shafighfard, T., Demir, E., Yildiz, M., 2019. Design of fiber-reinforced variable-stiffness composites for different open-hole geometries with fiber continuity and curvature constraints. Composite Structures 226, 111280. URL: http: //www.sciencedirect.com/science/article/pii/S0263822319318719, doi:https://doi.org/10.1016/j.compstruct.2019.111280.

[219] Shah, S.Z., Karuppanan, S., Megat-Yusoff, P.S., Sajid, Z., 2019. Impact resistance and damage tolerance of fiber reinforced composites: A review. doi:10.1016/j.compstruct.2019.03.021.

[220] Shen, Y., Branscomb, D., 2020. Orientation optimization in anisotropic materials using gradient descent method. Composite Structures 234, 111680. URL: http: //www.sciencedirect.com/science/article/pii/S0263822319333215, doi:10.1016/j.compstruct.2019.111680.

[221] Sherburn, M., Long, A.C., 2010. TexGen open source project. Online at http://texgen. sourceforge. net .

[222] Shiino, M.Y., Pelosi, T.S., Cioffi, M.O.H., Donadon, M.V., 2017. The Role of Stitch Yarn on the Delamination Resistance in Non-crimp Fabric: Chemical and Physical Interpretation. Journal of Materials Engineering and Performance 26, 978-986. doi:10.1007/s11665-0162460-2.

[223] Sigmund, O., 2001. A 99 line topology optimization code written in matlab. Structural and Multidisciplinary Optimization 21, 120-127. doi:10.1007/s001580050176.

[224] da Silva, A.L.F., Salas, R.A., Nelli Silva, E.C., Reddy, J.N., 2020. Topology optimization of fibers orientation in hyperelastic composite material. Composite Structures 231, 111488. URL: http://www.sciencedirect.com/science/article/pii/ S0263822319306786, doi:10.1016/j.compstruct.2019.111488.

[225] Silver, M.J., Hinkle, J.D., Peterson, L.D., 2004. Modeling of snapback bending response of doubly slit cylindrical shells, in: Collection of Technical Papers - AIAA/ASME/ASCE/AHS/ASC Structures, Structural Dynamics and Materials Conference, pp. 3314-3327.

[226] Simeoli, G., Acierno, D., Meola, C., Sorrentino, L., Iannace, S., Russo, P., 2014. The role of interface strength on the low velocity impact behaviour of PP/glass fibre laminates. Composites Part B: Engineering 62, 88-96. doi:10.1016/j.compositesb.2014.02.018.

[227] Sonnenfeld, C., Mendil-Jakani, H., Agogué, R., Nunez, P., Beauchêne, P., 2017. Thermoplastic/thermoset multilayer composites: A way to improve the impact damage tolerance of thermosetting resin matrix composites. Composite Structures 171, 298-305. doi:10.1016/j.compstruct.2017.03.044.

[228] Sorrentino, L., Sarasini, F., Tirillò, J., Touchard, F., Chocinski- 
Arnault, L., Mellier, D., Russo, P., 2017a. Damage tolerance assessment of the interface strength gradation in thermoplastic composites. Composites Part B: Engineering 113, 111-122. doi:10.1016/ j.compositesb.2017.01.014.

[229] Sorrentino, L., de Vasconcellos, D.S., D’Auria, M., Sarasini, F., Tirillò, J., 2017b. Effect of temperature on static and low velocity impact properties of thermoplastic composites. Composites Part B: Engineering 113, 100-110. doi:10.1016/j.compositesb.2017.01.010.

[230] de Sousa, B.S., Gomes, G.F., Jorge, A.B., da Cunha, S.S., Ancelotti, A.C., 2018. A modified topological sensitivity analysis extended to the design of composite multidirectional laminates structures. Composite Structures 200, 729746. URL: http://www.sciencedirect.com/science/article/pii/ S0263822318307487, doi:10.1016/j.compstruct.2018.05.145.

[231] Soykasap, Ö., 2009. Deployment analysis of a self-deployable composite boom. Composite Structures 89, 374-381. doi:10.1016/ j.compstruct.2008.08.012.

[232] Soykasap, Ö., Pellegrino, S., Howard, P., Notter, M., 2008. Folding large antenna tape spring. Journal of Spacecraft and Rockets 45, 560-567. doi:10.2514/1.28421.

[233] Soykasap, Ö., Watt, A.M., Pellegrino, S., 2004. New deployable reflector concept, in: Collection of Technical Papers AIAA/ASME/ASCE/AHS/ASC Structures, Structural Dynamics and Materials Conference, pp. 683-693. doi:10.2514/6.2004-1574.

[234] Stegmann, J., Lund, E., 2005. Discrete material optimization of general composite shell structures. International Journal for Numerical Methods in Engineering 62, 2009-2027. doi:10.1002/nme.1259.

[235] Steinboeck, A., Jia, X., Hoefinger, G., Mang, H.A., 2008. Conditions for symmetric, antisymmetric, and zero-stiffness bifurcation in view of imperfection sensitivity and insensitivity. Computer methods in applied mechanics and engineering 197, 3623-3636.

[236] Svanberg, K., 1987. The method of moving asymptotes-a new method for structural optimization. International Journal for Numerical Methods in Engineering 24, 359-373. doi:10.1002/nme.1620240207.

[237] Szyszkowski, W., Fielden, K., Johnson, D.W., 1997. Self-locking satellite boom with flexure-mode joints. Applied Mechanics Reviews 50, S225-S231. doi:10.1115/1.3101840.

[238] Tan, L.T., Pellegrino, S., 2006. Thin-shell deployable reflectors with collapsible stiffeners part 1: Approach. AIAA Journal 44, 2515-2523. doi:10.2514/1.16320.

[239] Tan, L.T., Pellegrino, S., 2012. Thin-shell deployable reflectors with collapsible stiffeners: Experiments and simulations. AIAA Journal 50, 659-667. doi:10.2514/1.J051254.

[240] Tan, W., Falzon, B.G., 2016a. Modelling the crush behaviour of thermoplastic composites. Composites Science and Technology 134, 57-71. doi:10.1016/j.compscitech.2016.07.015.

[241] Tan, W., Falzon, B.G., 2016b. Modelling the nonlinear behaviour and fracture process of AS4/PEKK thermoplastic composite under shear loading. Composites Science and Technology 126, 60-77. doi:10.1016/j.compscitech.2016.02.008.

[242] Tan, W., Falzon, B.G., Chiu, L.N., Price, M., 2015. Predicting low velocity impact damage and Compression-After-Impact (CAI) behaviour of composite laminates. Composites Part A: Applied Science and Manufacturing 71, 212-226. doi:10.1016/ j.compositesa.2015.01.025.

[243] Tan, W., Falzon, B.G., Price, M., Liu, H., 2016. The role of material characterisation in the crush modelling of thermoplastic composite structures. Composite Structures 153, 914-927. doi:10.1016/ j.compstruct.2016.07.011.

[244] The SAMTECH Team, 2012. SAMCEF User Manual. LMS Samtech

[245] Tie, Y., Hou, Y., Li, C., Meng, L., Sapanathan, T., Rachik, M., 2020. Optimization for maximizing the impact-resistance of patch repaired CFRP laminates using a surrogate-based model. International Journal of Mechanical Sciences 172, 105407. URL: http://www.sciencedirect.com/science/article/pii/ s0020740319340081, doi:10.1016/j.ijmecsci.2019.105407.

[246] Tong, X., Ge, W., Gao, X., Li, Y., 2019a. Optimization of Combining
Fiber Orientation and Topology for Constant-Stiffness Composite Laminated Plates. Journal of Optimization Theory and Applications 181, 653-670. URL: https://doi.org/10.1007/s10957-018-1433-z, doi:10.1007/s10957-018-1433-z.

[247] Tong, X., Ge, W., Gao, X., Li, Y., 2019b. Simultaneous optimization of fiber orientations and topology shape for composites compliant leading edge. Journal of Reinforced Plastics and Composites 38, 706716. URL: https://doi.org/10.1177/0731684419842292, doi:10.1177/ 0731684419842292.

[248] Tong, X., Ge, W., Zhang, Y., Zhao, Z., 2019c. Topology design and analysis of compliant mechanisms with composite laminated plates. Journal of Mechanical Science and Technology 33, 613-620. doi:10.1007/s12206-019-0115-6.

[249] Tzeng, G.H., Huang, J.J., 2011. Multiple attribute decision making: Methods and applications. CRC press.

[250] Umer, R., Alhussein, H., Zhou, J., Cantwell, W.J., 2017. The mechanical properties of 3D woven composites. Journal of Composite Materials 51, 1703-1716. doi:10.1177/0021998316681187.

[251] Van Der Heijden, A.M., 2008. W. T. Koiter's elastic stability of solids and structures. volume 9780521515. Cambridge University Press Cambridge, UK:. doi:10.1017/Св09780511546174.

[252] Van Dijk, N.P., Maute, K., Langelaar, M., Van Keulen, F., 2013. Level-set methods for structural topology optimization: A review. Structural and Multidisciplinary Optimization 48, 437-472. doi:10.1007/s00158-013-0912-y.

[253] Verschelde, J., 1999. Algorithm 795: PHCpack: A general-purpose solver for polynomial systems by homotopy continuation. ACM Transactions on Mathematical Software 25, 251-276. doi:10.1145/ 317275.317286.

[254] Vieille, B., Casado, V.M., Bouvet, C., 2014. Influence of matrix toughness and ductility on the compression-after-impact behavior of woven-ply thermoplastic- and thermosetting-composites: A comparative study. Composite Structures 110, 207-218. doi:10.1016/ j.compstruct.2013.12.008.

[255] Viquerat, A.D., 2020. A continuation-based method for finding laminated composite stacking sequences. Composite Structures 238, 111872. URL: http://www.sciencedirect.com/science/article/pii/ S0263822319340310, doi:10.1016/j.compstruct.2020.111872.

[256] Vyvyan, W.W., 1968. Self-actuating, self-locking hinge.

[257] Walker, S.J., Aglietti, G., 2003. A study into the dynamics of three dimensional tape spring folds. 44th AIAA/ASME/ASCE/AHS/ASC Structures, Structural Dynamics, and Materials Conference 42, 850856.

[258] Wang, D., Abdalla, M.M., Wang, Z.P., Su, Z., 2019. Streamline stiffener path optimization (SSPO) for embedded stiffener layout design of non-uniform curved grid-stiffened composite (NCGC) structures. Computer Methods in Applied Mechanics and Engineering 344, 1021-1050. URL: http://www.sciencedirect.com/science/article/ pii/s0045782518304560, doi:10.1016/j.cma.2018.09.013.

[259] Wang, H.R., Long, S.C., Zhang, X.Q., Yao, X.H., 2018a. Study on the delamination behavior of thick composite laminates under lowenergy impact. Composite Structures 184, 461-473. doi:10.1016/ j.compstruct.2017.09.083.

[260] Wang, M., Cao, M., Wang, H., Siddique, A., Gu, B., Sun, B., 2017. Drop-weight impact behaviors of 3-D angle interlock woven composites after thermal oxidative aging. Composite Structures 166, 239-255. doi:10.1016/j.compstruct.2017.01.046.

[261] Wang, X.J., Zhang, X.A., 2014. Topology optimization of microstructures of cellular material based on the properties of macrostructures. Gongneng Cailiao/Journal of Functional Materials 45, 18078-18082. doi:10.3969/j.issn.1001-9731.2014.18.016.

[262] Wang, Y., Zhang, J., Fang, G., Zhang, J., Zhou, Z., Wang, S., $2018 b$. Influence of temperature on the impact behavior of woven-ply carbon fiber reinforced thermoplastic composites. Composite Structures 185, 435-445. doi:10.1016/j.compstruct.2017.11.056.

[263] Wang, Y., Zhang, J., Zhang, J., Zhou, Z., Fang, G., Wang, S., 2018c. Compressive behavior of notched and unnotched carbon woven-ply PPS thermoplastic laminates at different tempera- 
tures. Composites Part B: Engineering 133, 68-77. doi:10.1016/ j.compositesb.2017.09.027.

[264] Warren, P.A., Dobson, B.J., Hinkle, J.D., Silver, M., 2005. Experimental characterization of lightweight strain energy deployment hinges, in: Collection of Technical Papers AIAA/ASME/ASCE/AHS/ASC Structures, Structural Dynamics and Materials Conference, pp. 103-110. doi:10.2514/6.2005-1809.

[265] Watt, A.M., 2003. Deployable Structures with Self-locking Hinges. URL: http://ethos.bl.uk/OrderDetails.do?uin=uk.bl.ethos. 426505.

[266] Whitcomb, J., Srirengan, K., 1996. Effect of various approximations on predicted progressive failure in plain weave composites. Composite Structures 34, 13-20. doi:10.1016/0263-8223(95/00125-5.

[267] Wittrick, W.H., Williams, F.W., 1974. Buckling and vibration of anisotropic or isotropic plate assemblies under combined loadings. International Journal of Mechanical Sciences 16, 209-239. doi:10.1016/0020-7403(74/90069-1.

[268] Woodward, M.R., Stover, R., 2020. Damage tolerance. Composites 21.

[269] Wu, C., Viquerat, A., 2017. Natural frequency optimization of braided bistable carbon/epoxy tubes: Analysis of braid angles and stacking sequences. Composite Structures 159, 528-537. doi:10.1016/ j.compstruct.2016.09.075.

[270] Wu, J., Luo, Z., Li, H., Zhang, N., 2017. Level-set topology optimization for mechanical metamaterials under hybrid uncertainties. Computer Methods in Applied Mechanics and Engineering 319, 414441. doi:10.1016/j.cma.2017.03.002.

[271] Wu, Y., Li, E., He, Z.C., Lin, X.Y., Jiang, H.X., 2020. Robust concurrent topology optimization of structure and its composite material considering uncertainty with imprecise probability. Computer Methods in Applied Mechanics and Engineering 364, 112927. URL: http://www.sciencedirect.com/science/article/pii/ S0045782520301109, doi:10.1016/j.cma.2020.112927, arXiv:1910.09365.

[272] Wu, Z., Xia, L., Wang, S., Shi, T., 2019. Topology optimization of hierarchical lattice structures with substructuring. Computer Methods in Applied Mechanics and Engineering 345, 602-617. URL: http://www.sciencedirect.com/science/article/pii/ S0045782518305589, doi:10.1016/j.cma.2018.11.003.

[273] Xia, L., Breitkopf, P., 2015. Multiscale structural topology optimization with an approximate constitutive model for local material microstructure. Computer Methods in Applied Mechanics and Engineering 286, 147-167. doi:10.1016/j.cma.2014.12.018.

[274] Xie, Y.M., Steven, G.P., 1997. Basic evolutionary structural optimization, in: Evolutionary structural optimization. Springer, pp. $12-29$.

[275] Xu, Y., Zhu, J., Wu, Z., Cao, Y., Zhao, Y., Zhang, W., 2018. A review on the design of laminated composite structures: constant and variable stiffness design and topology optimization. Advanced Composites and Hybrid Materials 1, 460-477. doi:10.1007/s42114018-0032-7.

[276] Yan, X., Huang, X., Zha, Y., Xie, Y.M., 2014. Concurrent topology optimization of structures and their composite microstructures. Computers and Structures 133, 103-110. doi:10.1016/ j.compstruc.2013.12.001.

[277] Yan, X., Xu, Q., Hua, H., Huang, D., Huang, X., 2019a. Concurrent topology optimization of structures and orientation of anisotropic materials. Engineering Optimization , 1-14URL: https://doi.org/ 10.1080/0305215X.2019.1663186, doi:10.1080/0305215X.2019.1663186.

[278] Yan, X., Xu, Q., Huang, D., Zhong, Y., Huang, X., 2019b. Concurrent topology design of structures and materials with optimal material orientation. Composite Structures 220, 473480. URL: http://www.sciencedirect.com/science/article/pii/ S0263822318339151, doi:10.1016/j.compstruct.2019.04.028.

[279] Yang, H., Lu, F., Guo, H., Liu, R., 2019. Design of a new N-Shape composite ultra-thin deployable boom in the post-buckling range using response surface method and optimization. IEEE Access 7, 129659-129665. doi:10.1109/ACCESS.2019.2934744.

[280] Yasaee, M., Bigg, L., Mohamed, G., Hallett, S.R., 2017. Influence of Z-pin embedded length on the interlaminar traction response of multi-directional composite laminates. Materials and Design 115, 26-36. doi:10.1016/j.matdes.2016.11.025.

[281] Yee, J.C., Pellegrino, S., 2005. Composite tube hinges. Journal of Aerospace Engineering 18, 224-231. doi:10.1061/(ASCE/08931321 (2005/18:4(224/.

[282] Yoo, K., Bacarreza, O., Aliabadi, M.H.F., 2021. Multi-fidelity robust design optimisation for composite structures based on low-fidelity models using successive high-fidelity corrections. Composite Structures 259, 113477.

[283] Yoon, K., Hwang, C.L., 2011. Multiple Attribute Decision Making. volume 104. Sage publications. doi:10.4135/9781412985161.

[284] You, Z., Pellegrino, S., 1996. Cable-stiffened pantographic deployable structures part 1: Triangular mast. AIAA Journal 34, 813-820. doi:10.2514/3.13144.

[285] Yue, N., Khodaei, Z.S., Aliabadi, M.H., 2021. Damage detection in large composite stiffened panels based on a novel SHM building block philosophy. Smart Materials and Structures 30, 45004.

[286] Zerbst, U., Beretta, S., Köhler, G., Lawton, A., Vormwald, M., Beier, H.T., Klinger, C., Černý, I., Rudlin, J., Heckel, T., Klingbeil, D., 2013. Safe life and damage tolerance aspects of railway axles - A review. Engineering Fracture Mechanics 98, 214-271. doi:10.1016/ j.engfracmech.2012.09.029.

[287] Zhang, W., Yang, J., Xu, Y., Gao, T., 2014. Topology optimization of thermoelastic structures: Mean compliance minimization or elastic strain energy minimization. Structural and Multidisciplinary Optimization 49, 417-429. doi:10.1007/s00158-013-0991-9.

[288] Zhang, Y., Gao, L., Xiao, M., 2020a. Maximizing natural frequencies of inhomogeneous cellular structures by Kriging-assisted multiscale topology optimization. Computers and Structures 230, 106197. URL: http://www.sciencedirect.com/science/article/pii/ S0045794919315299, doi:10.1016/j.compstruc.2019.106197.

[289] Zhang, Y., Xiao, M., Gao, L., Gao, J., Li, H., 2020 b. Multiscale topology optimization for minimizing frequency responses of cellular composites with connectable graded microstructures. Mechanical Systems and Signal Processing 135, 106369. URL: http://www.sciencedirect.com/science/article/pii/ S0888327019305904, doi:10.1016/j.ymssp.2019.106369.

[290] Zhang, Y., Xiao, M., Zhang, X., Gao, L., 2020c. Topological design of sandwich structures with graded cellular cores by multiscale optimization. Computer Methods in Applied Mechanics and Engineering 361, 112749. URL: http://www.sciencedirect.com/science/article/ pii/S0045782519306395, doi:10.1016/j.cma.2019.112749.

[291] Zhao, L., Li, K., Chang, Y., Li, J., 2019. Topology Optimization Design of Compliant Mechanism of Composite Wing Leading Edge, in: Journal of Physics: Conference Series, IOP Publishing. p. 12002. doi:10.1088/1742-6596/1215/1/012002.

[292] Zhou, K., Li, X., 2008. Topology optimization for minimum compliance under multiple loads based on continuous distribution of members. Structural and Multidisciplinary Optimization 37, 49-56. doi:10.1007/s00158-007-0214-3.

[293] Zhou, Y., Nomura, T., Saitou, K., 2018. Multi-component topology and material orientation design of composite structures (MTOC). Computer Methods in Applied Mechanics and Engineering 342, 438-457. URL: http://www.sciencedirect.com/science/article/pii/ S0045782518303839, doi:10.1016/j.cma.2018.07.039.

[294] Zhu, B., Zhang, X., Liu, M., Chen, Q., Li, H., 2019. Topological and Shape Optimization of Flexure Hinges for Designing Compliant Mechanisms Using the Level Set Method. Chinese Journal of Mechanical Engineering (English Edition) 32, 1-12. doi:10.1186/s10033-019-0332-z.

[295] Zhu, B., Zhang, X., Zhang, H., Liang, J., Zang, H., Li, H., Wang, R., 2020. Design of compliant mechanisms using continuum topology optimization: A review. doi:10.1016/j.mechmachtheory.2019.103622. 